\title{
Modeling the relationships between cognitive-linguistic skills and literacy skills: new insights from a transparent orthography
}

Article

Accepted Version

Babayigit, S. and Stainthorp, R. (2011) Modeling the relationships between cognitive-linguistic skills and literacy skills: new insights from a transparent orthography. Journal of Educational Psychology, 103 (1). pp. 169-189. ISSN 00220663 doi: https://doi.org/10.1037/a0021671 Available at https://centaur.reading.ac.uk/19573/

It is advisable to refer to the publisher's version if you intend to cite from the work. See Guidance on citing.

To link to this article DOI: http://dx.doi.org/10.1037/a0021671

Publisher: American Psychological Association

Publisher statement: This article may not exactly replicate the final version published in the APA journal. It is not the copy of record

All outputs in CentAUR are protected by Intellectual Property Rights law, including copyright law. Copyright and IPR is retained by the creators or other copyright holders. Terms and conditions for use of this material are defined in the End User Agreement. 


\section{CentAUR}

Central Archive at the University of Reading

Reading's research outputs online 
Modeling the Relationships between Cognitive-Linguistic Skills and Literacy Skills: New Insights from a Transparent Orthography 


\begin{abstract}
In this one-year longitudinal study, we examined the central component processes of reading fluency, spelling accuracy, reading comprehension, and narrative text writing skills of 103 Turkish Cypriot children. Two cohorts of children from second and fourth grades were followed into third and fifth grades, respectively. The testing battery included the measures of phonological awareness, rapid automitized naming (RAN), vocabulary, listening comprehension, and working memory. In line with previous research evidence from other transparent orthographies, such as German (Mann \& Wimmer, 2002), we have also found that while phonological awareness was the strongest predictor of spelling, RAN was a powerful predictor of reading fluency. The overall pattern of relationships were broadly in line with the models of reading comprehension and writing in English and further highlighted the central role of oral language skills in children's comprehension and writing. The results have also underscored the complexity of the relationships between reading fluency and reading comprehension and likewise, between transcription skills and writing quality. Finally, it has become clear from the findings that there is a need for an integrated and comprehensive approach to the study of reading comprehension and writing. Taken together, the overall results suggested that alongside many similarities, there are distinct differences in the way in which different component processes are related to different literacy skill that can be further influenced by the nature of the input language and orthography.
\end{abstract}

Keywords: reading fluency, spelling, reading comprehension, narrative text writing, listening comprehension 


\section{Modeling the Relationships between Cognitive-Linguistic Skills and Literacy Skills: New Insights from a Transparent Orthography}

It is widely acknowledged that research on different writing systems is the way forward in order to develop further our understanding of the complex relationships between language, cognition, and literacy (Joshi \& Aaron, 2006). Studies on reading and spelling development have reported some similar as well as some major differences between English and transparent orthographies with consistent grapheme-phoneme relationships, such as Turkish, Dutch, Finnish, and German (Babayiğit \& Stainthorp, 2009; de Jong \& van der Leij, 1999; Müller \& Brady, 2001; Wimmer \& Mayringer, 2002). While considerable attention has been focused on word level reading and spelling skills in transparent writing systems, much less attention has been focused on higher level literacy skills of reading comprehension and composition writing.

The current study seeks to address this issue in the context of the Turkish language, and examines not only basic reading and spelling skills but also extends the research focus to reading comprehension and narrative text writing skills. Turkish is also one of the very few alphabetic writing systems where the reading and spelling systems are relatively symmetrically transparent. In other widely examined transparent writing systems, such as German, Greek, and Dutch, phoneme-to-grapheme correspondences can be many-to-one, rendering spelling more complex than reading. Hence, research on Turkish also enables a systematic investigation of the orthographic transparency in both reading and writing.

\section{Reading and Spelling: The Relative Roles of RAN and Phonological Awareness}

Phonological awareness and RAN are central to the theories of reading (Torgesen, Wagner, \& Rashotte, 1994; Wolf, Bowers, \& Biddle, 2000). It is also widely acknowledged that phonological awareness and RAN relate to similar as well as distinct subprocessing skills that 
underlie reading development (Bowers \& Newby-Clark, 2002; Powell, Stainthorp, Stuart, Garwood, \& Quinlan, 2007; Savage \& Frederickson, 2005). Specifically, phonological awareness has been found to be more closely related to reading accuracy and RAN to reading fluency (or speed) (Savage \& Frederickson, 2005).

Although broader language skills have also been found to be important in word reading, there is a consensus that phonological awareness is one of the key language skills that underlie the development of word reading skills (for a review, see McCardle, Scarborough, \& Catts, 2001). This is evidenced by a wealth of data illustrating that phonological awareness is a powerful longitudinal predictor of individual differences in word reading skills in English (e.g., Lonigan, Burgress, \& Anthony, 2000; Muter, Hulme, Snowling, \& Stevenson, 2004; Wagner et al., 1997). However, the effect of phonological awareness in consistent orthographies seems to be transient and mostly redundant in predicting future reading performance, once letter knowledge or the autoregressor effect of previous reading skills are taken into account (e.g., Babayiğit \& Stainthorp, 2007; Verhagen, Aarnoutse, \& Van Leeuwe, 2008; Wimmer \& Mayringer, 2002). Instead, RAN has been found to be the most reliable and consistent predictor of reading in transparent systems, such as Turkish, Dutch, and German (e.g., Babayiğit \& Stainthorp, 2009; de Jong \& van der Leij, 1999; Verhagen et al., 2008; Wimmer \& Mayringer, 2002). It is still a matter of debate as to what actually RAN measures and why it is linked to reading fluency (Bowers \& Newby-Clark, 2002; Powell et al., 2007; Wolf et al., 2000). Nonetheless, there is some consensus that the rapid processing (i.e., activation and retrieval) of orthographic representations is possibly the key common component that underlies the strong relationships between RAN and reading speed (see Powell et al., 2007; Wolf et al., 2000). 
The theories of reading development emphasize the importance of letter knowledge and analytical processes (e.g., phonological awareness) in early reading acquisition or accurate decoding of words, which are then superseded by orthographic processing of letter strings as a global whole for accurate and fast reading (i.e., skilled word recognition) (e.g., Ehri, 1997; Frith, 1980; Share, 1995). Viewed in this way, the divergent findings observed between English and transparent systems can be explained in terms of the facilitative effect of a simple writing system on the development of word reading accuracy, which seems to render the role of phonological awareness skills largely redundant in word reading skills beyond the early stages (Wimmer \& Mayringer, 2002). In fact, word reading fluency rather than word reading accuracy is a more reliable measure of single word reading skills in transparent orthographies (Wimmer, 1993, 1996). This seems to be the primary reason why RAN, which is a more powerful predictor of reading fluency than phonological awareness (Savage \& Frederickson, 2005), tends to be the most reliable and consistent longitudinal predictor of reading fluency in transparent systems (e.g., Babayiğit \& Stainthorp, 2009; de Jong \& van der Leij, 1999; Georgiou, Parilla, \& Papadopoulos, 2008; Landerl \& Wimmer, 2008; Verhagen et al., 2008; Wimmer \& Mayringer, 2002).

Research on spelling in transparent orthographies is far more limited than reading. Nonetheless, there are several lines of research evidence from Turkish, German, and Dutch that have reported a sharp divergence between the predictors of reading and spelling (Babayiğit \& Stainthorp, 2007, 2009; van Bon \& van Leeuwe, 2003; Wimmer \& Mayringer, 2002). In a study in German, for instance, Wimmer and Mayringer (2002) followed children from kindergarten to Grade 3 and found that while kindergarten phonological awareness skills predicted later spelling performance, RAN was the most reliable and consistent predictor of reading fluency skills. 
Likewise, Babayiğit and Stainthorp (2009) followed Turkish-speaking children from Grade 1 to Grade 2 and found very similar results to those reported in German: RAN was the strongest predictor of reading speed and phonological awareness was found to play a central role in spelling skills. The differential effect of phonological awareness on reading and spelling in this study, in fact corroborates previous findings in Turkish whereby phonological awareness assessed prior to any formal reading instruction at kindergarten was found to be a powerful predictor of later spelling skills, but not reading skills (Babayiğit \& Stainthorp, 2007).

Although the theories of reading and spelling concur that spelling and reading are based on the same lexical representations and that both involve phonological and orthographic processing of words, it is also widely acknowledged that spelling differs from reading in several ways (Ehri, 1997; Perfetti, 1997). For instance, accurate spelling is more difficult than reading as it requires access to precise or explicit lexical representations of standard language and more sophisticated levels of phonological processing skills for the rapid processing of transient speech sounds (Perfetti, 1997; Treiman \& Barry, 2000). Whereas accurate reading can be accomplished with less complete information and based on partial knowledge of the alphabet (Ehri, 1997). It is for this reason that phonological processing is considered to play even more significant role in spelling than reading (Bosman \& van Orden, 1997; Perfetti, 1997; Treiman, 1993). The findings from the two studies in Turkish (i.e., Babayiğit \& Stainthorp, 2007, 2009) provided further support for the proposed special relationship between spelling and phonological processing skills and also suggested that irrespective of the level of orthographic consistency, phonological processing skills play a central role in spelling development (Babayiğit, 2009; Treiman \& Kessler, 2005; cf. Wimmer \& Mayringer, 2002). 
At this point, however, it should be emphasized that there is some evidence for small, albeit reliable relationships between RAN and spelling skills independent of phonological skills both in English (Savage, Pillay, \& Melidona, 2008; Savage \& Frederickson, 2006) and German (Landerl \& Wimmer, 2008). However, relatively less research attention has focused on the link between RAN and spelling. Although it has been posited that RAN is specifically linked to orthographic (i.e., word-specific) spelling, to date the exact nature of this relationship is far from clear (for a fuller discussion, see Savage et al., 2008).

Taken together, the research on transparent writing systems has highlighted that the developmental relationships between phonological awareness, RAN, word reading accuracy, reading fluency, and spelling may differ as a function of the consistency of the letter-sound relationships, as well as the speed of development of these skills. Nonetheless, given the limited research evidence in this area, further research needs to confirm these findings in symmetrically transparent writing systems, and examine to what extent the strong link observed between spelling and phonological skills can also be demonstrated among older age groups.

\section{Reading Comprehension}

The simple view of reading positions decoding accuracy and oral language comprehension skills as two central components of reading comprehension and provides a foundational framework for further analysis of the subcomponents of reading comprehension skills (Gough, Hoover, \& Peterson, 1996; Gough \& Tunmer, 1986; Hoover \& Gough, 1990). Research on English has shown that among beginning readers, decoding skills explain a very large proportion of variance in reading comprehension levels and as word reading accuracy increases with age, linguistic comprehension skills become the most powerful predictor (Chen \& Vellutino, 1997; Francis, Fletcher, Catts, \& Tomblin, 2005; Gough et al., 1996). In other words, 
once the mechanics of word reading reach a certain level of proficiency, they cease to constrain the comprehension processes.

Children's reading accuracy reaches above the $90 \%$ level after about one year of formal reading instruction in a transparent orthography (Seymour, Aro, \& Erskine, 2003). This is regarded as the level of word reading accuracy that needs to be achieved in order to be able to comprehend a given text (i.e., instructional level) (e.g., see Lipson \& Wixson, 2003). Hence, $90 \%$ of reading accuracy marks the point at which word level reading skills are no longer expected to constrain reading comprehension processes. This seems to be the primary reason why some studies have found listening comprehension rather than word reading accuracy skills to be the most powerful predictor of reading comprehension skills even among first graders in highly consistent orthographies, such as Turkish (Öney \& Durgunoğlu, 1997).

Along with reading accuracy, reading fluency has also been associated with effective reading comprehension skills. The definition of reading fluency and explanations of the nature of its relationship with reading comprehension varies according to different theoretical perspectives (for reviews, see Fuchs, Fuchs, Hosp, \& Jenkins, 2001; Kuhn \& Stahl, 2003; Wolf \& KatzirCohen, 2001). The automacity (LaBerge \& Samuels, 1974) and the verbal efficiency (Perfetti \& Lesgold, 1977; Perfetti \& Roth, 1981) theories posit that automatic and accurate reading free the limited attentional resources of children so that they can engage in higher levels of comprehension processes, such as inference making and integration. Others emphasize the multidimentional nature of reading fluency (e.g., prosody, expressiveness) and propose a more complex model of relationships between reading fluency and reading comprehension processes (Kintsch, 1998; Walczyk, 1994, 2000; Wolf \& Katzir-Cohen, 2001). For instance, the compensatory encoding model states (Walczyk, 2000) that some children may read more slowly 
but engage in active comprehension strategies, such as comprehension monitoring, and inference making that in turn support the comprehension processes. Conversely, some children may read fast and accurately but do not engage in active processing of text that may undermine their comprehension and recall of the text. Syntactic and semantic processing skills may also influence reading fluency and mediate its relationship with the comprehension processes (see Klauda \& Guthrie, 2008; Kuhn \& Stahl, 2003). Finally, as Kintsch's (1998) construction-integration model of reading comprehension postulates, text level characteristics and background knowledge may also modulate the relationship between reading fluency and comprehension.

Within the context of this study, reading fluency is used to refer to accurate and fast reading, which is a narrow but most widely studied aspect of reading fluency (Kuhn \& Stahl, 2003). Recall that reading fluency is also a more reliable index of individual differences in word level reading skills in transparent orthographies. However, so far, the evidence in relation to the link between reading fluency and reading comprehension in transparent orthographies is highly limited and inconclusive. Several studies in Finnish reported very weak relationships between reading fluency and reading comprehension even among first and second graders (e.g., Dufva, Niemi, \& Voeten, 2001; Müller \& Brady, 2001). In both of these studies, listening comprehension was the most powerful predictor of early reading comprehension levels. There are, however, reports of stronger relationships between reading fluency and reading comprehension in other transparent orthographies, such as Dutch. In this study, de Jong and van der Leij (2002) followed children from first to third grade. They tested children's reading skills with a one minute reading task and found that after controlling for the autoregressor (Grade 1 reading comprehension skills) both word reading and listening comprehension skills explained unique variances in Grade 3 reading comprehension levels. 
At this point, it is important to highlight that similar inconsistent findings have also been reported in English (e.g., Adolf, Catts, \& Little, 2006; Cutting \& Scarborough, 2006; Jenkins, Fuchs, van den Broeck, Espin, \& Deno, 2003; Klauda \& Guthrie, 2008; Proctor, Carlo, August, \& Snow, 2005; Spear-Swerling, 2006) and there is ongoing debate about the precise role of reading fluency in reading comprehension development (see Kuhn \& Stahl, 2003; Paris, Carpenter, Paris, \& Hamilton, 2005). For instance, while Jenkins et al. (2003) reported powerful relationships between reading fluency and reading comprehension skills, Adolf et al. (2006) found that after controlling for word reading accuracy and listening comprehension, reading fluency failed to account for any reliable variance in reading comprehension levels among children at the fourth and eighth grades (Adolf et al., 2006). It is notable that in this study, due to near perfect correlations between the reading fluency and reading accuracy scores, it was not possible to analyze their independent contributions to reading comprehension levels at the second grade. In fact, it has been argued that the strong covariance between reading accuracy and reading fluency measures specially among younger age groups may give a misleading picture about the independent role of reading fluency in reading comprehension development (Paris et al., 2005).

Research on transparent writing systems may provide important insights in this regard. Due to the rapid development of word reading accuracy, the effect of reading fluency on reading comprehension development can be investigated relatively independently from the limiting effects of word level decoding skills even among younger age groups. Given the educational importance attached to fast and accurate word reading at primary grade levels (Good \& Kaminski, 2002; NICHD, 2000) and the assumption that reading fluency skills reflect overall reading competence (e.g., Fuchs et al., 2001), there are obvious educational implications of 
increasing our understanding of the developmental relationships between reading fluency and comprehension skills (see Kamhi, 2009a, 2009b; Samuels, 2006).

The simple view of reading is essentially a developmental account of reading comprehension with a specific focus on the evolving relationships between word reading, oral language comprehension, and reading comprehension skills (Gough et al., 1996). Understanding of reading comprehension, as a process of construction of a coherent mental representation of text, however, requires a much complex framework that takes into account the roles of background knowledge, general language skills (e.g., vocabulary), inference making processes, comprehension strategies, knowledge of text structure, working memory as well as their complex inter-relationships (see Graesser \& Britton, 1996; McNamara, 2007; Oakhill \& Cain, 2007; Perfetti, Landi, \& Oakhill, 2005). The multifaceted nature of the processes involved in reading comprehension constitutes a major challenge for the development of theoretical models of reading comprehension acquisition that can capture all these complex relationships (Perfetti et al., 2005). It is also primarily for this reason that research in this area tends to focus on a subset of component processes of comprehension. In this paper, we have focused on vocabulary knowledge and verbal working memory skills.

There is an abundance of research evidence that has shown powerful relationships between vocabulary knowledge and reading comprehension skills (e.g., Beck, Perfetti, \& McKeown, 1982; Catts, Adlof, \& Weismer, 2006; de Jong \& van der Leij, 2002; NICHD, 2005; Ouellette, 2006; Protopapas, Sideridis, Mouzaki, \& Simos, 2007; Seigneuric \& Ehrlich, 2005; Torgesen, Wagner, Rashotte, Burgess, \& Hecht, 1997). This seems to be a complex and multifaceted relationship (for reviews, see Anderson \& Freebody, 1981; Nagy, 2007; Wagner, Muse, \& Tannenbaum, 2007). Nonetheless, at a basic level, vocabulary knowledge can influence 
reading comprehension at least in two ways: directly through its effect on semantic processing of the text as well as indirectly through its effect on word reading skills. Poor vocabulary along with poor oral language comprehension skills have also been consistently found to characterize children with specific reading comprehension difficulties (e.g., see Catts, Hogan, \& Fey, 2003; Nation, Clarke, Marshall, \& Durand, 2004). These children can read words relatively accurately but show poor reading comprehension skills (Aaron, 1989; Gough \& Tunmer, 1986).

As reading comprehension entails complex integrative processes, it has been specifically linked with complex working memory skills. The explanations about the relationship between working memory and reading comprehension may differ depending on the theoretical conceptualisation of working memory (e.g., Baddeley \& Hitch, 1974; Daneman \& Carpenter, 1980; Engle, Kane, \& Tuholski, 1999; Ericsson \& Kintsch, 1995). However, working memory can be broadly conceptualized as a limited-capacity processing system that enables simultaneous processing and integration of multiple sources of information for effective comprehension (Daneman \& Carpenter, 1980) and has been linked to both language and attentional control skills (for a review, see Carretti, Borella, Cornoldi, \& De Beni, 2009).

Most studies in this area tend to be cross-sectional and the research evidence is far from conclusive. Several cross-sectional studies on children at primary grade levels have found working memory to be a reliable predictor of individual differences in reading comprehension levels even after controls of IQ, vocabulary, and reading skills (e.g., Cain, Oakhill, \& Bryant, 2004; Gottardo, Stanovich, \& Siegel, 1996; Seigneuric, Ehrlich, Oakhill, \& Yuill, 2000;

Swanson \& Berninger, 1996). There are, however, reports of unreliable or weak relationships as well (e.g., Goff, Pratt, \& Ong, 2005; Nation, Adams, Bowyer-Crane, \& Snowling, 1999; Stothard \& Hulme, 1992). Longitudinal research examining the developmental relationship 
between working memory and comprehension skills among typical populations is very limited and so far, the available research evidence from younger children has revealed weak relationships (e.g., Seigneuric \& Ehrlich, 2005). For instance, Seigneuric and Ehrlich (2005) followed children from first to third grade. They have found no statistically reliable longitudinal relationships between Grade 1 working memory and Grade 2 reading comprehension skills. However, when tested at Grade 2, working memory explained a small unique variance (4\%) in Grade 3 reading comprehension levels over and above the measures of word reading, vocabulary, and autoregressor (Grade 2 reading comprehension). Hence, the results from this study indicated a developmental increase in the strength of the relationships between verbal working memory and reading comprehension skills. One possible reason for this developmental trend could be the tendency of the reliability of working memory scores to increase with age, as these tasks are very difficult for younger children (see Pickering \& Gathercole, 2001). Taken together, it is clear that further research is needed to clarify the evolving relationships between word reading, oral language, verbal working memory, and reading comprehension skills among typical populations.

\section{Narrative Text Writing}

Analogous to reading comprehension, writing is also a highly complex process and involves the integration and coordination of multiple lower and higher level processing skills, including spelling, oral language skills (e.g., vocabulary knowledge, grammatical awareness), working memory (e.g., attentional control), discourse knowledge, and higher-level metacognitive skills, such as self-regulation (for reviews, see Graham \& Perin, 2007; Hayes, 2006; McCutchen, 2006). The triangle model conceives writing as a product of transcription (e.g., spelling accuracy and writing fluency), text generation (translation of ideas into language), and executive processes 
(e.g., self-regulation, attention) that take place in a dynamic working memory environment with direct links to both long-term memory and short-term memory (Berninger, 2000; Berninger \& Graham, 1998). Efficient transcription skills are considered to free the limited attentional or working memory resources of the children and enable them to focus on the generation of ideas and then, translation of these ideas into grammatical sentences as well as other higher level writing processes. Hence, it is conceived that transcription skills can influence writing quality, through its indirect effect on the text generation processes as well as direct effect on writing fluency (Berninger et al., 1992; Graham, 1990).

The important role of transcription processes in writing quality has been illustrated by a large number of studies at primary grades as well as higher grade levels (e.g., Berninger et al., 1992; Christensen \& Jones, 2000; Connelly, Dockrell, \& Barnett, 2005; Connelly \& Hurst, 2001; Graham, Berninger, Abbot, Abbot, \& Whitaker, 1997; Olinghouse, 2008; Stainthorp \& Rauf, 2009). At this point it is important to note that different transcription skills may play a different role along the trajectory of writing development. In a comprehensive review study, it has been found that while both handwriting fluency and spelling accuracy explained moderate to large variances in writing quality at primary grades, only handwriting fluency made unique contribution to writing skills among older age groups: the effect of spelling was time-limited to primary grades (Graham et al., 1997). Stainthorp and Rauf (2009) tested 421 children aged between 9 and 11 years and reported similar developmental trends. While the effect of spelling accuracy declined with age, that of handwriting fluency increased. Hence, these findings suggested that once spelling accuracy levels reach a certain threshold, they seem to cease to constrain the writing processes. In contrast, handwriting speed seems to continue to influence writing quality beyond the early stages of writing development. 
Turning to oral language skills, there is no question that oral language skills, such as vocabulary knowledge are central to the text generation process and have been found to be sensitive and powerful predictors of writing quality (Baker, Gersten, \& Graham, 2003; Bishop \& Clarkson, 2003; Olinghouse \& Leaird, 2009; Roth, 2000). For instance, in a recent study, Olinghouse and Leaird (2009) tested the narrative writing skills of two groups of children at second and fourth grades, and found that along with compositional (writing) fluency, vocabulary, which was assessed in terms of diversity of word knowledge, was the most powerful and consistent predictor of compositional quality at both age groups. Oral language is envisaged to influence writing skills through its direct effect on the translation of ideas into grammatical sentences as well as indirectly through its facilitative effect on working memory functions (McCutchen, Covill, Hoyne, \& Mildes, 1994). It is explained that fluency in translation of generated ideas into words and sentences reduces the processing demands on working memory and thereby, frees up the conscious attentional processes for the generation of further ideas or other higher level writing processes (e.g., revision) (McCutchen et al., 1994). This brings the discussion to the role of working memory in writing.

Working memory lies at the heart of the writing process and is envisaged as a dynamic system whereby the multiple subcomponent processes of writing are coordinated and integrated (e.g., Bereiter \& Scardamalia, 1987; Berninger \& Graham, 1998; Kellogg, 1999; McCutchen, 1996; Ransdell \& Levy, 1996). There is a large body of research evidence in support of the central role of working memory in writing production in both children and adults (e.g., Berninger et al., 1992; Bourdin \& Fayol, 1994; Olive \& Kellogg, 2002; Swanson \& Berninger, 1996). However, most of these studies are experimental and cross-sectional studies, and there is surprisingly very limited longitudinal investigation on the developmental relationship between 
working memory and writing skills among typical populations. The writing research on languages other than English is also highly limited.

So far, the available research on composition writing in transparent systems has yielded mixed findings. For instance, Babayiğit and Stainthorp (2009) followed children from Grade 1 to Grade 2 and examined longitudinal predictive roles of oral language (vocabulary and grammatical skills), transcription (spelling accuracy, writing error rate, writing fluency), and working memory skills in children's early writing development in Turkish. In line with previous research, they found working memory and vocabulary to be the strongest predictors of children's later writing quality and their effect was evident even when grammatical and spelling accuracy skills were taken into account. However, in contrast to the findings in some studies in English (e.g., Berninger et al., 1992), they found no reliable relationships between any of the transcription skills and writing quality measures. Similar unreliable relationships between spelling accuracy and writing quality have also been reported in a longitudinal study in Finnish (Maki, Voeten, Vauras, \& Poskiparta, 2001). Both studies associated the observed weak relationships between spelling and narrative text writing with the simplicity of the spelling systems of Turkish and Finnish, which did not seem to constrain the text generation processes even during the very early stages of literacy development. However, given the paucity of research in consistent orthographies, further longitudinal investigations of writing skills need to confirm these findings and clarify to what extent methodological or orthographic differences may underlie some of the observed discrepant findings in the literature.

\section{Overview of the Current Study and the Key Predictions}


In this longitudinal study, we tested Turkish Cypriot children's reading fluency, spelling accuracy, reading comprehension, and narrative text writing skills with an extensive battery of measures. There were three main aims.

Firstly, we sought to replicate the previous findings in relation to the differential roles of RAN and phonological awareness in reading and spelling in transparent orthographies and examine to what extent these patterns of relationships are observed among older age groups. Based on previous research (e.g., Babayiğit \& Stainthorp, 2009; Wimmer \& Mayringer, 2002), we anticipated that while phonological awareness would be a powerful longitudinal predictor of spelling skills, RAN would be the most powerful predictor of reading fluency.

Secondly, we sought to take the simple view of reading further and examine the roles of reading fluency, listening comprehension, vocabulary, and verbal working memory skills in reading comprehension. In view of the previous findings in Finnish and Turkish, it was anticipated that listening comprehension would be the most powerful predictor and make direct as well as indirect effects on later reading comprehension. However, due to the rapid development of word reading skills in Turkish, word reading was expected to play a modest role in reading comprehension (see Müller \& Brady, 2001; Öney \& Durgunoğlu, 1997). We also anticipated that the effects of vocabulary and working memory on later reading comprehension performance would be indirect through their relationships with the concurrent measures of listening comprehension and reading comprehension.

Finally, with this study, we sought to examine the triangle model of writing in the context of the Turkish language. More specifically, we examined the relative role of transcription (spelling accuracy, writing accuracy, and writing fluency), oral language (vocabulary knowledge), and verbal working memory skills in narrative text writing. Limited research 
impedes making precise predictions. Nonetheless, based on available research evidence from Turkish, English, and Finnish, we anticipated that there would be reliable relationships between children's verbal working memory, vocabulary, and writing quality. However, in view of the previous findings in Turkish and Finnish (see Babayiğit \& Stainthorp, 2009; Maki et al., 2001), we anticipated that the transcription skills would play a limited role in children's writing quality.

\section{Method}

\section{Participants}

One hundred and nine children were tested at Grade $2(N=52)$ and Grade $4(N=57)$, and then re-tested about nine months later when they were at Grade 3 and Grade 5, respectively. Six participants failed to complete the study due to either illness or moving. Here, we present the findings from the remaining 103 children who completed the study. In the resultant sample, there were 48 children at Grade 2 (23 females and 25 males; mean age $=93.70$ months, $S D=3.91$, age range $=87-100$ months $)$ and 55 children at Grade 4 (29 females and 25 males; mean age $=$ 116.89 months, $S D=3.34$, age range $=109-122$ months $).$

Children came from two public primary schools in Northern Cyprus. The sample reflected a good range of socio-economic backgrounds (see SPO, 1996). The percentages of parents from different occupational backgrounds were $4.5 \%$ professional, $15.5 \%$ self-employed, $39 \%$ nonmanual worker, $7 \%$ skilled manual worker, $9 \%$ partially skilled manual worker, and $25 \%$ unemployed/houseworker. As regards to the educational backgrounds of the parents, the percentages were also diverse and reflected the general population patterns in Northern Cyprus: $0 \%$ none, $21.5 \%$ primary school, $7 \%$ secondary school, $56.5 \%$ high school, $11.5 \%$ university and $3.5 \%$ postgraduate. Turkish is the only official language and the education is centrally controlled in Northern Cyprus. The primary schools follow a set curriculum and generally use the same 
instructional materials distributed freely by the Ministry of Education. For this reason, teaching across the schools tends to be relatively uniform. Children were randomly selected from the classrooms on the conditions that they spoke Turkish as their first language and did not have any formally diagnosed neurological, speech or language impairments.

\section{Materials and Procedures}

Children were tested individually in a quiet classroom at their schools over two sessions. Each testing session lasted for about 50 minutes and the data collection for each wave of testing was completed within four-to-five weeks. All testing was conducted by the first author who is Turkish Cypriot and a native speaker of Turkish. Standardized measures of IQ, short-term memory (STM), and vocabulary were administered. The remaining measures were experimental measures developed and piloted by the first author, as there were no standardised alternative tests in Turkish that could have been used at the time of testing. In this study, IQ and STM were used as control measures in order to account for any variance in the literacy outcome measures that may be associated with general reasoning and simple verbal memory skills.

General IQ. Raven's Standardized Progressive Matrices (Raven, 1967) was used as a test of general reasoning skills. In this test, a pattern with a missing part is presented and the task is to choose one option, which completes the target pattern. Formal testing procedures as outlined in the testing manual were followed. The reported test-retest reliability of the scores on this test for populations under 30 years of age is .93 ( Raven, Court, \& Raven, 2006). Due to the lack of standardized norms for Northern Cyprus at the time of testing, the inferential statistical analysis was conducted with age-adjusted standardized scores.

Vocabulary. Expressive vocabulary skills were assessed by the vocabulary subset of the Turkish version of the WISC-R (Savaşır \& Şahin, 1995). The split-half internal consistency of 
the scores on this subtest has been reported to range from .89 to .92 (Savaşır \& Şahin, 1995). Standard testing and scoring procedures were implemented.

STM. The forward digit span subtest from the Turkish version of WISC-R (Savaşır \& Şahin, 1995) has been used to assess verbal STM skills, which was implemented in accordance with the formal guidelines. The split-half internal reliability of the scores on this measure was .97 at Grade 2 and .90 at Grade 4.

Phonological awareness. Three tasks were developed to assess phonological awareness skills. These were sound oddity, phoneme deletion, and spoonerism tasks. At the beginning of each task four practice trials with feedback were given. No feedback was provided for the test trials. A score was awarded for each correct response. Examples of these tasks are presented in the Appendix. These tasks have been widely used in English (e.g., see Frederickson, 1996), however, given the lack of standardized tests of phonological awareness in Turkish, the use of multiple measures of phonological processing skills with different levels of complexity aimed to provide a more comprehensive and reliable assessment of phonological awareness skills. The observed strong correlations among the three phonological measures ( $r$ s ranging from .59 to .67 , see Table 2) provided support for the concurrent construct validity of these measures.

Sound oddity. Three single syllable words were presented orally and the task was to identify the odd-one-out (adapted from Bradley \& Bryant, 1983). The target odd word differed from the remaining two words in terms of its either rime or onset component. There were 21 test trials. The internal consistency of the scores on this measure was high for both groups: the Cronbach's alpha coefficient was .87 at Grade 2 and .82 at Grade 4.

Phoneme deletion. This was based on Bruce's sound analysis task (Bruce, 1964). A nonword was articulated, which was then followed by a target to-be-deleted phoneme. There 
were nine items in this task and the to-be-deleted phoneme was either in word initial (three items), final (three items) or medial positions (three items). After the deletion, the remaining part was also a nonword. The Cronbach's alpha coefficient was .76 at Grade 2 and .84 at Grade 4.

Spoonerism. In this task, 12 pairs of single syllable nonwords were presented and the task was to transpose their first sounds. After the transformation, the nonwords became real words. The scores revealed high internal consistency: the alpha coefficient was .80 at Grade 2 and .91 at Grade 4.

RAN. Digit and letter naming tasks were used to assess rapid naming skills (adapted from Denckla \& Rudel, 1974). The letters were a, o, s, d, p and the digits were 3, 5, 4, 8, 7. For each task, there were two trials and the final score was the average score of the two trials (for further information, see Babayiğit \& Stainthorp, 2009). The alternate form reliability indices (Pearson's $r$ ) were very high: RAN-Digits, $r$ s $=.98$ at both Grade 2 and Grade 4; and RANLetters, $r=.99$ at Grade 2 and .97 at Grade 4. We have also observed strong relationships between the digit and letter naming tasks $(r=.79$, see Table 2$)$ that further confirmed the concurrent construct validity of these two naming speed measures.

Working memory. A modified version of the reading span task of Daneman and Carpenter (1980) was used as a measure of working memory skills. Children listened to a series of simple declarative sentences that they had to judge to be true or false. Then, they had to recall verbatim the first word of each sentence in the order of presentation. Two practice trials with one- and two-sentence sets were given at the beginning of the test (see Appendix). There were three trials in each set (two, three, four or five sentences in each set) and failure on two trials within a set resulted in the termination of the test. One point was scored for each correct trial. 
All the to-be recalled words were simple two-syllable words and the sentences were composed of two or three Turkish words (three or four morphemes). As Turkish is an agglutinative language with subject object verb word order, it was not possible to have words without affixes at the end of a sentence. For this reason, the standard procedure of the reading span task was modified and rather than the final word, the first word of each sentence was asked to be recalled. The scores showed high internal consistency and the split-half reliability values were .95 at Grade 2 and .97 at Grade 4.

Listening comprehension. The procedure for this task was based on the listening comprehension subtest of Wechsler Objective Language Dimensions test (Wechsler, 1996). Five short passages were read aloud to children. The length of the passages ranged from one- to foursentences (10 - 36 words). There were a total of 14 oral questions designed to tap both inference making skills as well as verbatim recall of literal information from the passages. Each passage was read aloud once in normal prosody. The Cronbach's alpha coefficient of the scores was .67 at both second and fourth grades and the removal of any individual items did not increase the alpha value. However, as the observed alpha coefficient was very close to the desirable criterion of .7, the internal consistency of the scores can be considered acceptable for the purposes of this study. There were also strong concurrent and longitudinal relationships between listening comprehension and reading comprehension measures in this study $(r \mathrm{~s}=.56$ and .59 , see Tables, 2 and 4, respectively) that provided support for the concurrent construct validity of this measure.

Reading fluency. Reading fluency was assessed by three different single word reading tasks and two text reading tasks.

Word reading fluency. Three different one-minute word reading tasks with real nonagglutinated words (i.e., real words without affixes), pronounceable nonwords, and real 
agglutinated words (i.e., real words with affixes) were developed. The list of real agglutinated words was included in order to capture the full range of word types encountered in Turkish, which is a highly inflected language. In each case, the words were presented as a list on an A4 size card. The task was to read aloud accurately and as fast as possible until asked to stop. The score was the total number of accurately read words in one minute (for further information, see Babayiğit \& Stainthorp, 2007; 2009).

The test-retest reliability coefficients (after nine months) of scores for both younger (i.e., the cohort tested at Grade 2 and Grade 3) and older cohorts (i.e., the cohort tested at Grade 4 and Grade 5) were very high: Word reading, $r=.90$ for younger and .92 for older cohorts; Nonword reading, $r=.91$ for younger and .94 for older cohorts; Agglutinated word reading, $r=.89$ for younger and .90 for older cohorts.

Text reading fluency. We obtained a measure of text reading fluency based on the two narrative passages used to assess reading comprehension skills as described below. The task was to read aloud each passage carefully. The final score was average score on each passage recorded in terms of the total number of accurately read words in one minute. The test-retest reliability of the text reading fluency after nine months was .87 for younger group tested at the second grade and .89 for the older group tested at the fourth grade.

The three single word reading measures and text reading fluency measures shared large variances at both testing times ( $r$ s ranging from .79 to .89 , see Tables 2 and 3 ) that replicates previous research in Turkish (e.g., Babayiğit \& Stainthorp, 2009) and further confirms the concurrent construct validity of the reading fluency measures. Finally, it is notable that text reading accuracy was at ceiling levels ( $97 \%$ for both groups at all testing points) and was not 
related to reading comprehension at any point of testing. For this reason, text reading accuracy was not included in the analysis.

Reading comprehension. Reading comprehension skills were assessed by three narrative passages. Two passages involved reading aloud (length $=70$ words and 104 words) and one silent reading (length $=79$ words). There were a total of 26 oral questions designed to tap inference making skills as well as verbatim recall of the text. The passage was taken away when answering the questions. The use of multiple measures of reading comprehension that involved both silent reading and reading-aloud protocols aimed to provide a more reliable assessment of reading comprehension skills. A pilot study on 20 children from four primary grade levels (i.e., grades $2,3,4$, and 5) confirmed that it was not possible to answer the questions in the absence of having read the text (see Keenan \& Betjemann, 2006) and that there was a good range of scores across all grade levels.

The reading comprehension measure also showed adequate internal consistency and the Cronbach's alpha coefficients were .76 at Grade 2, .81 at Grade 3, .80 at Grade 4, and .74 at Grade 5. The test - retest reliability index of reading comprehension was. 68 for the younger cohort tested at the second grade and .69 for the older cohort tested at the fourth grade. Finally, as noted before there were strong relationships between listening comprehension and reading comprehension providing support for the concurrent validity of the comprehension measures (see Tables 2 and 4).

Spelling. Thirteen pronounceable nonwords were used to asses spelling accuracy skills. For instance, <füt>/fyt/, <tamar>/tamar/, <kurp>/kurp/, and <talbank>/talbank/. Nonwords were used in order to assess children's ability to spell novel words and control for any individual differences in spelling levels that may reflect differences in prior experience with text. Due to the 
transparency of Turkish spelling system and limited cases of orthographic (word-specific) spellings, there is only one possible correct spelling for each nonword and therefore, the use of nonwords provides a strict and sensitive index of spelling skills. Each item was repeated twice by the experimenter and the task was to write the nonword down as accurately as possible. In order to increase task sensitivity, items with different levels of linguistic complexity (e.g., word-final consonant clusters) were developed (see Babayiğit, 1999; Çapan, 1989).

The alpha coefficients were .73 at Grade 2, .70 at Grade 3, .74 at Grade 4, and .79 at Grade 5. The test-retest reliability of spelling accuracy after nine months was also high: $r=.50$ for the younger group tested at Grade 2 and $r=.74$ for the older cohort tested at Grade 4 . It is also notable that modified versions of this task had been used in previous research in Turkish, where it was found to be a reliable index of individual differences in spelling skills (see Babayiğit \& Stainthorp, 2007, 2009).

Narrative text writing. Young children's knowledge of narrative genre is more advanced than expository genre, possibly due to their more extensive experience with narrative stories from a very early age (Givon, 1979; Sulzby, 1985) and this seems to be one of the main reasons why children perform better on narrative writing tasks than expository writing tasks (Hidi \& Hildyard, 1983). Hence, the research on young children's writing skills tends to focus on narrative writing. In order to facilitate the comparison of the results, we have also focused on children's narrative writing development.

Children were presented with a series of eight pictures on an A4 size card. The picture story was about a hiking trip. The children were first told to examine the pictures and then, to start writing the story. They were also instructed to cross out any error and rewrite next to it. There were no time restrictions on this task. The total time taken to complete the writing task 
was recorded. The written passages were scored in terms of fluency, spelling error rate, and quality of the content (for further information, see Babayiğit \& Stainthorp, 2009).

Writing error rate. Writing error rate was calculated by dividing the total number of words with spelling errors by the total number of written words.

Writing fluency. Writing fluency was scored in terms of total number of words written in one minute.

Writing content. The quality of the content of the written compositions was assessed in terms of the overall accuracy and clarity of the depiction of the events in the pictures, and the appropriate use of vocabulary. The accuracy and clarity of the written outputs was scored on a scale of 1 to 5 ranging from 'very poor-mostly irrelevant information' to 'very good-accurate, vivid and highly detailed explanations of the depicted events', and the appropriateness of the choice of vocabulary was scored on a scale of 1 to 4 ranging from 'very poor-lacks precision and may be inappropriate' to 'very rich-appropriate and specific that conveys the meaning accurately' (this was based on the vocabulary subscale of the written expression part of the Wechsler Individual Achievement Text-Second UK Edition, Wechsler, 2005).

As the legibility of handwriting may influence the rating of overall compositional quality (Graham \& Weintraub, 1996), the handwritten texts were word processed, before being scored independently by two experienced primary school teachers in Northern Cyprus, who had been trained on the scoring protocol by the first author. Any spelling errors and cross-outs were retained in the typed scripts. The final score for the writing content was the average of the scores given by the two teachers. The first author acted as a third party and re-scored the scripts when there was a substantial discrepancy between the scores of the two raters. We have observed a substantial discrepancy between the scores (i.e., greater than one point of difference on the 
scores of either or both the clarity of expression and the appropriate use of vocabulary) in $8 \%$ of the cases (17 instances out of 206 scores). In these instances, the final score was determined by the third party.

The scores given by the two raters were very close to each on the measures of writing error rate and fluency, and the mean interrater reliability indices (Pearson's Product Moment correlation coefficient) for writing error rate and writing fluency were very high: writing error rate, $r=.98$ at Grade 2, and .97 at Grade 4; Writing fluency, $r=.93$ at Grade 2, and .96 at Grade

4. The interrater reliability indices for the writing content were .74 at Grade 2, .68 at Grade 3, .70 at Grade 4, and .72 at Grade 5. As there is an element of subjectivity in the scoring of quality, it tends to be more difficult to obtain high levels of consistency between the scorers. Nonetheless, these interrater reliability coefficients are generally considered acceptable in this area of research (see Graham \& Perin, 2007).

\section{Results}

\section{Preliminary Data Analysis: Descriptive Statistics, Distribution of the Data, and Outliers}

Table 1 shows a summary of descriptive statistic of the measures and time of testing. Only literacy outcome measures were implemented at Time 2. Preliminary diagnostic procedures were conducted in order to assess the normality of the distribution of the scores and outliers. Significant positive skews were observed on the writing-error rate measures at both second and fourth grades $\left(\right.$ Grade 2, $\mathrm{z}_{\text {skewness }}=6.39$, Grade $\left.4, \mathrm{z}_{\text {skewness }}=6.34, p s<.001\right)$ further confirming that the spelling error rates on the composition writing task were at floor levels. Spelling accuracy scores at Grade 5 were also negatively skewed $\left(\mathrm{Z}_{\text {skewness }}=-2.89, p<.01\right)$. However, there was a good range of scores on this measure (the scores ranged from 3 to 13, see Table 1), 
suggesting that the measure had adequate sensitivity to capture individual differences in spelling skills at Grade 5.

There were two outlying cases with low scores on the fifth grade spelling accuracy measure and one outlying low score on the single real word reading measure assessed at the third grade. Changing the outliers to the next highest score did not change the essence of the results. Likewise, the logarithm 10 transformation of the scores with skewed distributions (i.e., writing spelling error rate assessed at the second and fourth grade and spelling accuracy assessed at the fifth grade) did not change the results. For these reasons, we report the findings based on the untransformed raw scores.

It is notable that the observed mean reading fluency values were smaller than those reported in English (e.g., see Hasbrouck \& Tindal, 2006). This can largely be explained by task and language differences. In the single word reading tasks, along with high frequency singlesyllable words, children were also presented with low frequency and multisyllabic words even on the first few rows of the reading lists. In a one minute reading task, children do not read all the items, hence including both easy and more difficult items from the beginning of the word lists was considered important in order to ensure that irrespective of the speed of reading, all children were presented with words with a range of complexity. Yet, in many single word reading tasks in English either all simple single syllable items are used (e.g., Dynamic Indicators of Basic Oral Reading Fluency Skills, Good \& Kaminski, 2002) or the words lists are graded and more difficult items appear towards the end of the reading lists (e.g., Test of Word Reading Efficiency, Torgeson, Wagner, \& Rashotte, 1999). Likewise, although the words in the passages were high frequency, they were multisyllabic and highly inflected words that in turn contribute to a smaller 
word reading speed ratio in comparison with English. For instance, a sentence with four words in English, such as I gave the book, is written with two words in Turkish, Kitabl verdim.

\section{Correlational Analyses}

In this study, the pattern of correlations between the predictor and outcome measures across the two samples were very similar. For this reason, and for reasons of parsimony and simplicity of the presentation of data, the longitudinal data from these two samples of children were collapsed into a single sample. In other words, the children who were tested at the second and fourth grades were combined into a single group and their data represented the scores at Time 1. Likewise, the follow-up data at the third and fifth grades were combined to represent the Time 2 scores. Combining the two samples also served to increase the sample size, thereby the power of the statistical analysis. In order to account for the effect of age on the scores, age was controlled for in all subsequent data analyses.

Tables 2, 3, and 4 present a summary of the concurrent and longitudinal correlations between the measures after controlling for age. Although phonological awareness and vocabulary shared large variances with reading fluency, RAN was clearly the most powerful correlate of reading fluency (see Tables 2 and 4). Among the predictor measures, phonological awareness measures were the strongest correlates of spelling accuracy across both testing occasions (see Tables 2 and 4). In the case of reading comprehension, IQ, vocabulary, and listening comprehension were the strongest correlates. Finally, IQ, vocabulary, and working memory shared moderate to large variances with writing-content.

It is also notable that among the transcription skills, only spelling accuracy was most reliably related to writing content and shared a moderate variance of $35 \%$ with the writing content at Time 1 (see Table 2). However, their relationship became weaker and unreliable when 
they were tested at Time $2(r s=.20$, see Tables 3 and 4$)$. The relationships of writing error rate and fluency with writing content were unreliable across both testing occasions (see Tables 2 and 4).

There are clearly many inconsistent findings in the literature in relation to the role of general IQ and STM in literacy skills (e.g., see Stanovich, Cunningham, \& Freeman, 1984; Wagner et al., 1997). The correlation analyses of the data in Table 2 and Table 4 revealed that there were reliable and in certain cases strong relationships between IQ and literacy outcome measures. For this reason, it was considered appropriate to retain IQ as a control measure in the subsequent analyses in order to take into account any individual variations in literacy performance, which might be linked directly or indirectly to general IQ. However, the relationships between STM and the four main outcome measures were very weak and unreliable. Hence, for reasons of parsimony, STM was dropped from subsequent analyses.

\section{Formation of Composite Measures}

The observed strong relationships between the reading fluency measures and their similar pattern of relationships with the predictor measures, in effect, replicated the previous findings in Turkish, where the different types of word reading measures (i.e., single real word, nonword reading, agglutinated real word, and text reading speed) were also highly related to each other and the strength of their relationships with the predictors were also comparable (see Babayiğit $\&$ Stainthorp, 2007; Babayiğit \& Stainthorp, 2009). For this reason, and the economy of presentation, a reading fluency composite score was created by extracting a principal component from a factor analysis into which the scores on the three single word reading and the text reading tasks were entered. Likewise, in order to enhance reliability and reduce the number of estimated parameters in the subsequent path models, we have also created composite factor scores for 
phonological awareness and RAN measures. The correlation coefficients between the composite measures and other measures are also presented in Tables 2, 3, and 4.

\section{Structural Equation Modeling (SEM) Analyses}

A series of SEM analyses were conducted using the statistical software AMOS 17

(Arbuckle, 2008) in order to test the concurrent and longitudinal predictors of reading fluency, spelling accuracy, reading comprehension, and narrative text writing skills. The SEM analyses is considered the most effective way of testing the relative importance of correlated predictor measures and enables effective analysis of the mediating relationships (Kline, 2005).

We used the maximum likelihood estimation procedure for the path analysis. The chisquare fit index, Bentler's comparative fit index (CFI) and the root-mean-square error of approximation (RMSEA) were used to evaluate the goodness of fit of the sample data. A nonsignificant chi-square value indicates a good fit, likewise CFI values above .95 and a RMSEA value, which ranges less than .08 indicate adequate fit of the sample data to the hypothesized model (Browne \& Cudeck, 1993).

Figures 1, 2, 3, and 4 show the models depicting the hypothesized relationships between the constructs. All the predictor measures were allowed to correlate with each other. In order to control for the effect of age on any of the outcome measures, we have included direct paths from age to both Time 1 and Time 2 outcome measures ${ }^{1}$. In the figures, solid lines indicate statistically reliable standardized path weights, whereas broken lines indicate nonsignificant paths. The reported $R^{2}$ values in the figures represent structural variances. According to Cohen's (1988) rule of thumb, $R^{2}$ values less than .01 indicate small effect size, values around .09 medium effect size, and values larger than .25 large effect size. Likewise, based on the same criteria, standardized path coefficient values that are less than .10 can be considered to indicate small effect, values 
around .30, medium effect and those at or larger than .50 large effect (see Kline, 2005). Further details of the hypothesized relationships are outlined in the relevant sections for each literacy outcome measure ${ }^{2}$.

\section{Predictors of Reading Fluency}

Figure 1 shows the hypothesized relationships between the predictor variables and the concurrent and longitudinal measures of reading fluency. Reliable concurrent relationships between phonological awareness, vocabulary, and reading skills have been reported in both English and consistent writing systems, such as Turkish, Dutch, Greek, and Finnish (Babayiğit \& Stainthorp, 2009; de Jong \& van der Leij, 2002; Georgiou et al., 2008; Müller \& Brady, 2001) suggesting that irrespective of orthographic transparency, there are mutual facilitative relationships between these skills. Previous research has reported a powerful direct effect of RAN on later reading fluency as well as an indirect effect through its strong concurrent relationships with the autoregressor measure (i.e., concurrent measure of reading fluency) (Babayiğit \& Stainthorp, 2009; de Jong \& van der Leij, 1999; Georgiou et al., 2008; Verhagen et al., 2008). Hence, both paths were included in the hypothetical model. However, once again based on the previous findings in consistent orthographies, the effects of phonological awareness and vocabulary on subsequent measure of reading fluency were expected to be indirect and through the autoregressor (e.g., see Babayiğit \& Stainthorp, 2009; de Jong \& van der Leij, 2002; Landerl \& Wimmer, 2008).

The hypothesized model seemed to have provided an adequate fit to the observed data, $\chi^{2}$ $(3, N=103)=4.192, p=.241, \mathrm{CFI}=.998, \mathrm{RMSEA}=.058($ see Figure 1$)$. RAN was clearly the most powerful predictor of reading fluency. In this study, the autoregressor was a very powerful predictor and explained very large variance (standardized path weight $=.99$ ) in Time 2 reading 
fluency levels. This seems to be primary reason why RAN failed to make any reliable direct contributions to Time 2 reading fluency levels over and above the autoregressor. The overall model explained $90 \%$ of variance in Time 2 reading fluency.

\section{Predictors of Spelling}

Figure 2 shows the hypothesized path model for the predictors of Time 2 spelling accuracy. In view of the previous findings in relation to the powerful link between phonological awareness and spelling in Turkish and German (Babayiğit \& Stainthorp, 2007, 2009; Wimmer \& Mayringer, 2002), we anticipated that phonological awareness would be the most powerful predictor of spelling accuracy. For this reason, we included both direct as well as indirect paths from phonological awareness to Time 2 spelling.

The observed fit indices suggested that the model provided a very good fit for the sample data, $\chi^{2}(3, N=103)=2.946, p=.402, \mathrm{CFI}=1.00, \mathrm{RMSEA}=.000$ (Figure 2$)$. Phonological awareness was the most powerful predictor and made a direct unique contribution to Time 2 spelling levels as well as an indirect contribution through the autoregressor. RAN also explained smaller, albeit reliable unique variance in Time 1 spelling level. The overall model explained a total of $46 \%$ variance in Time 2 spelling performance.

\section{Predictors of Reading Comprehension}

It was hypothesized that listening comprehension, vocabulary, and verbal working memory would all make indirect contributions to Time 2 reading comprehension performance through their direct relationships with the autoregressor (i.e., Time 1 Reading comprehension). Listening comprehension, however, was expected to be the most powerful predictor and make direct contributions to Time 2 reading comprehension as well. These assumptions were informed by the previous studies, which have found (a) listening comprehension to be the most powerful 
longitudinal predictor of reading comprehension performance when word reading accuracy levels are high (de Jong \& van der Leij, 2002; Gough et al., 1996; Müller \& Brady, 2001; Öney \& Durgunoğlu, 1997); and (b) the longitudinal effects of vocabulary and other predictors on reading comprehension levels to be mediated through their relationship with the concurrent measures of listening comprehension and autoregressor (e.g., de Jong \& van der Leij, 2002).

Inconsistent findings in the literature impede making precise prediction about the role of reading fluency in reading comprehension. However, in view of the rapid development of word reading skills in Turkish, we anticipated that after taking into account oral language and cognitive skills, reading fluency would make a small contribution to later reading comprehension levels. The proposed model has adequately explained the sample data, $\chi^{2}(4, N=103)=5.500, p$ $=.240, \mathrm{CFI}=.996, \mathrm{RMSEA}=.061$, and the Time 1 predictor measures explained $51 \%$ variance in Time 2 reading comprehension levels (see Figure 3).

It is notable that when we deleted the nonsignificant path from reading fluency to Time 1 reading comprehension, the overall predictive power of the model remained the same (i.e., $51 \%$ of total explained variance) and the model fit indices slightly improved, $\chi^{2}(5, N=103)=5.565$, $p=.351, \mathrm{CFI}=.998, \mathrm{RMSEA}=.033$, the chi-square difference was not statistically significant, $\left.\Delta \chi^{2}(1, N=103)=0.065, p>.05\right)$. This finding further suggested that reading fluency was largely a redundant predictor measure in this model.

\section{Predictors of Narrative Text Writing}

Recall that among the measures of transcription skills, it was only Time 1 spelling accuracy that shared reliable variance with the writing content (see Table 2). For this reason, only spelling accuracy was included in the path model. Based on previous research, we expected vocabulary, working memory, and spelling accuracy to make direct contributions to writing 
content at Time 1. In view of the findings that oral language skills are particularly strongly related to writing skills (e.g., Babayiğit \& Stainthorp, 2009; Olinghouse \& Leaird, 2009), we also anticipated that vocabulary knowledge would be a powerful predictor and make direct as well as indirect contributions to Time 2 writing content. As Figure 4 shows, the model yielded a very good fit for the observed data, $\chi^{2}(3, N=103)=2.024, p=.568, \mathrm{CFI}=1.00, \mathrm{RMSEA}=.000$, and the overall model explained $35 \%$ of variance in Time 2 writing quality scores.

However, as the direct paths from IQ, vocabulary, and spelling failed to reach statistical significance, we tested the most parsimonious model fit (i.e., the model with reduced number of estimated parameters) by deleting the nonsignificant paths with the highest $p$ values until the moment the overall fit indices of the model indicated that further deletions would deteriorate the model fit. This process was informed by the statistical significance in the chi-square difference values as well as our a priori predictions about the direct and indirect effects of the predictor measures (see Kline, 2005). After the deletion of the nonsignificant paths from age and working memory, the magnitude of the $R^{2}$ remained the same (35\%) and fit indices hardly changed, $\chi^{2}(6$, $N=103)=5.676, p=.460, \mathrm{CFI}=1.00, \mathrm{RMSEA}=.000$. However, the path coefficients from vocabulary to Time 1 writing and Time 2 writing became .24 and .20 , respectively, which were all statistically significant at .05. In the case of spelling accuracy and IQ, the path coefficients hardly changed (the path coefficients were .20 and .21 , respectively) but the $p$ values approached significance in both cases $(p s=.051)$.

\section{Discussion}

This study examined the key components of reading fluency, spelling accuracy, reading comprehension, and text writing skills with a relatively wide range of measures in Turkish. It is widely acknowledged that longitudinal studies that take into account autoregressor effects are 
powerful designs that further our understanding of causal relationships (de Jong \& van der Leij, 2002; Gollob \& Reichardt, 1987). The relatively symmetrical consistency of Turkish also provided an appropriate medium to examine the role of orthographic transparency in both reading and writing, and thereby, further our understanding of the role of orthographic consistency in literacy development. It is also noteworthy that all the hypothesized models provided good fit to the observed data, whereby the values of RMSEA ranged from .00 to .06.

\section{Reading Fluency and Spelling}

In line with our predictions, while rapid naming was the most powerful predictor of word reading fluency, phonological awareness was the strongest predictor of spelling skills. Hence, the results replicated the previous findings in Turkish and German (Babayiğit \& Stainthorp, 2009; Wimmer \& Mayringer, 2002) and made a contribution to this area of research by illustrating that the differential relationship of phonological awareness skills with reading fluency and spelling can be observed in a relatively symmetrically transparent writing system and even among older primary school children.

As noted before, more precise phonological representations and sophisticated levels of speech analysis skills are required for spelling relative to reading (Perfetti, 1997; Treiman, 1993). Although, the Turkish spelling system is highly consistent, linguistic factors, such as assimilation (e.g., /t/ sounds as /p/ in <football>) and co-articulation arguably render spelling harder than reading in every language including Turkish. This may be the reason why despite a negative skew, we were able to obtain a relatively good range of spelling accuracy scores even among older age groups. Hence, overall findings are in line with the theories that have emphasized the central role of phonological processing skills in spelling development (Perfetti, 1997). 
Although the primary focus of the current paper was on the link between phonological processing and spelling skills, it is notable that the observed reliable relationship between RAN and spelling are in line with the previous findings in English (Savage et al., 2008) and German (Landerl \& Wimmer, 2008). It seems that even when the spelling system is highly consistent, it is still possible to find reliable relationships between RAN and spelling independent of phonological processing skills. This is clearly an important finding that warrants further investigation.

The observed pattern of the respective relationships of phonological awareness and RAN with reading fluency and spelling are clearly in line with the models of reading and spelling acquisition that emphasize the role of both analytic and orthographic processing of words (e.g., Ehri, 1997). It remains to be the major challenge of this area of research to clarify the exact nature of the relationship of RAN with reading fluency and spelling (Savage et al., 2008). Nonetheless, the findings from this study further signified that irrespective of orthographic transparency, there are clear pedagogical implications of teaching phonics and facilitating the development of phonological awareness skills, particularly in children's spelling development. Finally, the observed unique effect of RAN on both reading fluency and spelling, underscored the need to go beyond phonology and to further our understanding of other aspects of reading and spelling development that have the potential to inform literacy practices. particularly for children with specific literacy difficulties .

\section{Reading Comprehension}

As expected, listening comprehension emerged as the most powerful predictor and made direct unique contribution to later reading comprehension levels as well as indirect contribution through the autoregressor. Hence, the findings provided clear support for the simple view of 
reading and replicated those of the previous research in Turkish (Öney \& Durgunoğlu, 1997), Finnish (Dufva et al., 2001; Müller \& Brady, 2001), and Dutch (de Jong \& van der Leij, 2002). Likewise, the findings were in line with the expectation that the effects of vocabulary and verbal working memory on reading comprehension would be indirect through their concurrent relationships with listening and reading comprehension skills.

In this study, working memory shared moderate variances with listening and reading comprehension skills at both Time 1 and Time 2, which is in accordance with those reported in previous research (for reviews, see Carretti et al., 2009; Daneman \& Merikle, 1996). For this reason, its small and marginally nonsignificant unique contribution to reading comprehension can be partly explained by its strong relationships with other predictor measures ${ }^{3}$. Similar small unique effects sizes after controls of language skills have been reported before (e.g., Goff et al., 2005; Seigneuric \& Ehrlich, 2005). Hence, the findings highlighted the need for longitudinal studies with a specific focus on the key subcomponents of working memory, such as syntactic parsing, semantic processing, and executive inhibition skills in order to further our understanding of the developmental relationships between verbal working memory and reading comprehension skills (see Carretti et al., 2009).

Turning to reading fluency, its small and unreliable unique effect on reading comprehension was anticipated, and the findings concur with the previous research both in English and transparent writing systems (e.g., Adolf et al., 2006; Müller \& Brady, 2001; Proctor et al., 2005). Hence, the findings provided support for the notion that when the word reading accuracy levels are very high, reading fluency skills indexed by accurate and fast reading may give a misleading picture of the overall reading competence of children with important implications for their academic development (Kamhi, 2009b; Paris et al., 2005; Samuels, 2006). 
Although task specific factors might have partly contributed to these findings (e.g., see Best, Floyd, \& McNamara, 2008; Cutting \& Scarborough, 2006), overall findings in this study clearly suggest that a coherent understanding of the role of reading fluency in reading comprehension, requires a broader conceptualization of reading fluency skills that takes into account its multidimensional nature (e.g., prosody) as well as complex relationship with the comprehension processes (see Kintsch, 1998; Kuhn \& Stahl, 2003; Walczyk, 1994; Wolf \& Katzir-Cohen, 2001). Following from these findings, in a highly transparent orthography where high levels of decoding accuracy skills can be achieved very easily, poor readers seem to more likely to show the profile of children with specific reading comprehension difficulties (see Aaron, 1989; Catts et al., 2003).

Taken together, it has become clear from the findings in this study that there is need for an integrated approach to the study of component processes of comprehension .The observed finding that listening comprehension predicts children's reading comprehension levels is not informative unless we develop a better understanding the common component processes that underlie the observed powerful relationships between listening and reading comprehension. As Figure 3 suggested, vocabulary and verbal working memory explained some, but certainly not all of the strong variance between the two comprehension processes. This would suggest that there is a need for more comprehensive models of comprehension acquisition to be tested within a coherent theoretical framework that would further our understanding of the complex relationships between oral language (e.g., grammatical skills), metacognition (e.g., inference making and self-regulation), background knowledge, text characteristics (e.g., genre and coherence), and other individual factors (e.g., motivation) (for reviews, see Graesser \& Britton, 
1996; Guthrie \& Wigfield, 2005; Kintsch \& Kintsch, 2005; McNamara, 2007; Oakhill \& Cain, 2007; Perfetti et al., 2005).

\section{Writing}

As regards to narrative text writing skills, broadly, the model provided support for the triangle model of writing (Berninger, 2000; Berninger \& Graham, 1998) and our predictions. Vocabulary knowledge emerged as the most powerful predictor and made reliable direct as well as indirect contributions to Time 2 writing levels. This replicates previous findings in Turkish (Babayiğit \& Stainthorp, 2009) as well as in English (e.g., Olinghouse \& Leaird, 2009) and thereby, further highlights the central role of oral language skills in children's writing development. Although there were moderate bivariate relationships between working memory and writing content, working memory failed to explain any unique variance in writing: its effect on writing was completely mediated by its strong relationships with other predictor measures.

In this study, spelling accuracy showed a time-limited effect on Time 1 writing skills, which was marginally significant and it was not reliably related to writing content either longitudinally or concurrently at Time 2 (see Tables 3 and 4). This finding was anticipated and echoes the previous findings in Turkish (see Babayiğit \& Stainthorp, 2009) as well as the reports that there is a tendency of a time-limited relationship between spelling and writing skills (Graham et al., 1997; Stainthorp \& Rauf, 2009).

Weak relationships between writing-error rate and writing quality have been reported before both in Turkish as well as in English among primary school children (e.g., Babayiğit \& Stainthorp, 2009; Graham et al., 1997; Olinghouse, 2008). The possible bias to spell known words (Mackie \& Dockrell, 2004) and the observed skewed distribution of the scores with very restricted variance are the most likely explanations for these results (Graham et al., 1997). These 
findings further highlight the importance of assessing spelling skills independent of textgeneration processes.

Likewise, in this study, writing fluency was also not related to writing quality. This replicates the previous research in Turkish (Babayiğit \& Stainthorp, 2009) and provides support for the notion that the simplicity of Turkish spelling system along with the curricular emphasis on the systematic teaching of handwriting skills might have facilitated the development of transcription skills so much so that these lower level skills did not constrain text generation processes among typical populations (Babayiğit \& Stainthorp, 2009). Nonetheless, task-related factors might have also contributed to these findings. In this study, the writing task was not timed. The use a time-limited writing task might have yielded different results (e.g., see Graham et al., 1997; Olinghouse \& Leaird, 2009). Furthermore, writing fluency measures are confounded by text generation processes and therefore, a measure of handwriting fluency independent of the text generation processes is essential to clarify these findings (see Graham et al., 1997).

Although the model fit was very good and the overall model explained large (35\%) variance in writing quality, the overall effect size was smaller than those observed for other literacy outcome measures and a substantial amount of variance was left unaccounted for. This can be interpreted as partly reflecting the multicomponent nature of writing and the need for a more comprehensive research approach that also includes other higher level processing skills, such as self-regulation and knowledge of genre (see Graham \& Harris, 2000; McCutchen, 2006).

Although it is beyond the scope of the present paper to examine the relationships between writing and reading, it is notable that writing content in this study shared moderate to large variances with the measures of word reading, listening comprehension, and reading comprehension (see Tables 2, 3, and 4). Strong reciprocal relationships between reading 
comprehension and writing have been reported before (e.g., Abbott, Berninger, \& Fayol, 2010; Juel, 1988; Shanahan, 1984; Shanahan \& Lomax, 1986). Writing entails not only spelling but also reading. Also production and understanding of discourse share many common component processes, such as inference making (Fitzgerald \& Shanahan, 2000; Parodi, 2007). Viewed in this way, the findings further signified the importance of an integrated approach to the study of literacy development as well as the practice of literacy teaching (Abbott et al., 2010; Shanahan, 1984).

\section{General Limitations of the Study}

There are also several general limitations of the study that need to be noted. Firstly, as with any multivariate study, the findings of the current study are limited to the specific set of measures, we have used. Secondly, the observed strength of longitudinal relationships between the predictor and outcome measures can be influenced by the specific developmental period when they are tested as well as the duration of the time-lag between the testing periods (see Gollob \& Reichardt, 1987). In this study, the pattern of relationships across the two developmental periods (from Grade 2 to Grade 3 and from Grade 4 to grade 5) were comparable suggesting that similar processes were driving the development of the four literacy skills. Nonetheless, there was evidence of limited growth within as well as across the two cohorts specifically on the measures of reading comprehension and writing that could be due to a combination of factors including task-specific factors, sample differences, or the limited time-lag (nine months) between the two testing periods. Hence, further replication of this research across longer time-lags with a wider range of measures of comprehension and writing is needed and this should be borne in mind when evaluating the overall findings. Finally, the current study had the power to detect statistically reliable moderate to large effect sizes. There were strong 
relationships between some of the predictor measures. This, along with the observed powerful mediating effect of autoregressor measures in some models might have influenced the estimation of path coefficients and therefore, the observed marginally nonsignificant path coefficients should be treated with some caution.

\section{Conclusions}

The results from this study further contributed to the pool of research evidence showing that in a highly consistent spelling system RAN is the most reliable predictor of reading fluency, and that the strong relationships between phonological awareness and spelling skills can be observed even among older children. Hence, the findings are in line with the theories of reading and spelling development in English that emphasize the role of orthographic skills in reading fluency and phonological skills in spelling development (e.g., Bowers \& Newby-Clark, 2002; Ehri, 1997; Perfetti, 1997). Although the overall pattern of relationships in this study were in line with the simple view of reading and the triangle model of writing, they have also highlighted the complex relationships between reading fluency and reading comprehension, and likewise between transcription skills and writing quality. Finally, it has become clear from the findings that there is a need for an integrated and more comprehensive approach to the study of reading comprehension and composition writing. 


\section{References}

Aaron, P. G. (1989). Dyslexia and hyperlexia. Dodrecht, The Netherlands: Kluwer Academic Publishers.

Abbott, R. D., Berninger, V. W., \& Fayol, M. (2010). Longitudinal relationships of levels of language in writing and between writing and reading in grades 1 to 7 . Journal of Educational Psychology, 102, 281-298.

Adolf, S. M., Catts, H. W., \& Little, T. D. (2006). Should the simple view of reading include a fluency component? Reading and Writing: An Interdisciplinary Journal, 19, 933-958.

Anderson, R. C., \& Freebody, P. (1981). Vocabulary knowledge. In J. Guthrie (Ed.), Comprehension and teaching: Research reviews (pp. 77-117). Newark, DE: International Reading Association

Arbuckle, J. (2008). Amos 17 user's guide (Version 17.0 version): Spring House: Amos Development Corporation.

Babayiğit, S. (1999). The role of syllabic and phonemic awareness in reading and spelling skills of Turkish -speaking first graders. Unpublished Masters Dissertation, Institute of Education, University of London, London, U. K.

Babayiğit, S. (2009). Reading and spelling in transparent alphabetic orthographies: Points of convergence and divergence. In C. Wood \& V. Connelly (Eds.), Contemporary perspectives on reading and spelling (pp. 133-148). London: Routledge.

Babayiğit, S., \& Stainthorp, R. (2007). Preliterate phonological awareness and early literacy skills in Turkish. Journal of Research in Reading, 30, 394-413.

Babayiğit, S., \& Stainthorp, R. (2009). Component processes of early reading, spelling, and narrative writing skills in Turkish: A longitudinal study. Reading and Writing: An Interdisciplinary Journal doi:.Advanced online publication. doi: 10.1007/s11145-0099173

Baddeley, A. D., \& Hitch, G. J. (1974). Working memory. In G. H. Bower (Ed.), The psychology of learning and motivation (Vol. 8, pp. 47-89). New York: Academic Press.

Baker, S., Gersten, R., \& Graham, S. (2003). Teaching expressive writing to students with learning disabilities: Research-based applications and examples. Journal of Learning Disabililities, 36, 109-123.

Beck, I., Perfetti, C. A., \& McKeown, M. (1982). Effects of long-term vocabulary instruction on lexical access and reading comprehension Journal of Educational Psychology, 74, 506521.

Bereiter, C., \& Scardamalia, M. (1987). The psychology of written composition Hillsdale, NJ: Erlbaum.

Berninger, V. (2000). Development of language by hand and its connections to language by ear, mouth, and eye. Topics of Language Disorders, 20, 65-84.

Berninger, V., \& Graham, S. (1998). Language by hand: A synthesis of a decade of research on handwriting Handwriting Review, 12, 11-25.

Berninger, V. W., Yates, C., Cartwright, A., Rutberg, J., Remy, E., \& Abbot, R. (1992). Lowerlevel developmental skills in beginning writing. Reading \& Writing: An Interdisciplinary Journal 4, 257-280.

Best, R. M., Floyd, R. G., \& McNamara, D. S. (2008). Differential competencies contributing to children's comprehension of narrative and expository texts. Reading Psychology, 29, 137164. 
Bishop, D. V. M., \& Clarkson, B. (2003). Written language as a window into residual language deficits: A study of children with persistent and residual speech and language impairments. Cortex, 39, 215-237.

Bosman, A. M. T., \& van Orden, G. V. (1997). Why spelling is more difficult than reading. In C. A. Perfetti, L. Rieben \& M. Fayol (Eds.), Learning to spell: Research, theory, and practice across languages (Vol. 10, pp. 173-194). Mahwah, NJ: LEA.

Bourdin, B., \& Fayol, M. (1994). Is written language production more difficult than oral language production? A working memory approach. International Journal of Psychology, 29, 591-620.

Bowers, P. G., \& Newby-Clark, E. (2002). The role of naming speed within a model of reading acquisition. Reading and Writing: An Interdisciplinary Journal, 15, 109-126.

Bradley, L., \& Bryant, E. P. (1983). Categorising sounds and learning to read- a causal connection. Nature, 301, 419-521.

Browne, M. W., \& Cudeck, R. (1993). Alternative ways of assessing model fit. In K. A. Bollen \& J. S. Long (Eds.), Testing structural equation models (pp. 136-162). Newbury Park, CA: Sage.

Bruce, D. J. (1964). The analysis of word sounds by young children. British Journal of Educational Psychology, 34, 158-169.

Cain, K., Oakhill, J., \& Bryant, E. P. (2004). Children's reading comprehension ability: Concurrent prediction by working memory, verbal ability and component skills. Journal of Educational Psychology, 96, 31-42.

Çapan, S. (1989). A linguistic study of reading and writing disorders in Turkish, an agglutinative language. In P. G. Aaron \& R. M. Joshi (Eds.), Reading and writing disorders in different orthographic systems (pp. 191-202). Netherlands: Kluwer Academic Publishers.

Carretti, B., Borella, E., Cornoldi, C., \& De Beni, R. (2009). Role of working memory in explaining the performance of individuals with specific reading comprehension difficulties: A meta-analysis. Learning and Individual Differences, 19, 246-251.

Catts, H. W., Adlof, S. M., \& Weismer, S. E. (2006). Language deficits in poor comprehenders: A case for the simple view of reading. Journal of Speech, Language \& Hearing Research, 49, 278-293.

Catts, H. W., Hogan, T. P., \& Fey, M. E. (2003). Subgrouping poor readers on the basis of reading-related abilities. Journal of Learning Disabilities, 36, 151-164.

Chen, S. R., \& Vellutino, F. R. (1997). Prediction of reading ability: A cross-validation study of the simple view of reading. Journal of Literacy Research, 29, 1-24.

Christensen, C. A., \& Jones, D. (2000). Handwriting: An underestimated skill in the development of written language. Handwriting Today, 2, 56-69.

Cohen, J. D. (1988). Statistical power analysis for the behavioural sciences (2 ed.). Hillsdale, NJ: Erlbaum.

Cohen, J. D., \& Cohen, P. (1983). Applied multiple regression/correlation analysis for the behavioural sciences (2nd ed.). Hillsdale, NJ: Lawrence Erlbaum Publishers.

Connelly, V., Dockrell, J. E., \& Barnett, J. (2005). The slow handwriting of undergraduate students constrains overall performance in exam essays. Educational Psychology, 25, 99 107.

Connelly, V., \& Hurst, G. (2001). The influence of handwriting fluency on writing quality in later primary and early secondary education. Handwriting Today, 2, 5-55. 
Cutting, L. E., \& Scarborough, H. S. (2006). Prediction of reading comprehension: Relative contributions of word recognition, language proficiency, and other cognitive skills can depend on how comprehension is measured. Scientific Studies of Reading, 10, 277-299.

Daneman, M., \& Carpenter, P. A. (1980). Individual differences in working memory and reading. Journal of Verbal Learning and Verbal Behaviour, 19, 450-466.

Daneman, M., \& Merikle, P. M. (1996). Working memory and language comprehension: A metanalysis. Psychonomic Bulletin and Review, 3, 422-433.

de Jong, P. F., \& van der Leij, A. (1999). Specific contributions of phonological abilities to early reading acquisition: Results from a Dutch latent variable longitudinal study. Journal of Educational Psychology, 91, 450-476.

de Jong, P. F., \& van der Leij, A. (2002). Effects of phonological abilities and linguistic comprehension on the development of reading. Scientific Studies of Reading, 6, 51-77.

Denckla, M. B., \& Rudel, R. G. (1974). Rapid automatized naming of pictured objects, colors, letters, and numbers by normal children. Cortex, 10, 186-202.

Dufva, M., Niemi, P., \& Voeten, M. J. M. (2001). The role of phonological memory, word recognition, and comprehension skills in reading development: From preschool to grade 2. Reading and Writing: An Interdisciplinary Journal, 14, 91-117.

Ehri, L. C. (1997). Learning to read and learning to spell are one and the same, almost. In C. A. Perfetti, L. Rieben \& M. Fayol (Eds.), Learning to spell: Research, theory, and practice across languages (Vol. 13, pp. 237-268). Mahwah, NJ: Erlbaum.

Engle, R. W., Kane, M. J., \& Tuholski, S. W. (1999). Individual differences in working memory capacity and what they tell us about controlled attention, general fluid intelligence, and functions of the prefrontal cortex. In A. Miyake \& P. Shah (Eds.), Models of working memory (Vol. 4, pp. 102-127). Cambridge: Cambridge University Press.

Ericsson, K. A., \& Kintsch, W. (1995). Long-term working memory. Psychological Review, 102, 211-245.

Fitzgerald, J., \& Shanahan, T. (2000). Reading and writing relations and their development. Educational Psychologist, 35, 39-50.

Francis, D. J., Fletcher, J. M., Catts, H. W., \& Tomblin, J. B. (2005). Dimensions affecting the assessment of reading comprehension. In S. Paris \& S. A. Stahl (Eds.), Children's reading comprehension and assessment (pp. 369-394). London: Lawrence Erlbaum Associates.

Frederickson, N. (Ed.). (1996). Phonological assessment battery manual (Research Edition ed.). London: University College London.

Frith, U. (1980). Unexpected spelling problems. In U. Frith (Ed.), Cognitive processes in spelling (Vol. 22, pp. 495-515). London: Academic Press.

Fuchs, L. S., Fuchs, D., Hosp, M. K., \& Jenkins, J. R. (2001). Oral reading fluency as an indicator of reading competence: A theoretical, empirical, and historical analysis. Scientific Studies of Reading, 5, 239-256.

Georgiou, G., Parilla, R., \& Papadopoulos, T. (2008). Predictors of word decoding and reading fluency across languages varying in orthographic consistency. Journal of Educational Psychology, 100, 566-580.

Givon, T. (1979). From discourse to syntax: Grammar as a processing strategy. In T. Givon (Ed.), Syntax and semantics: Discourse and syntax (Vol. 12, pp. 81-109). New York: Academic Press. 
Goff, D. A., Pratt, C., \& Ong, B. (2005). The relations between children's reading comprehension, working memory, language skills, and components of reading decoding in a normal sample. Reading and Writing: An Interdisciplinary Journal, 18, 583-616.

Gollob, H. F., \& Reichardt, C. S. (1987). Taking account of time lags in causal models. Child Development, 58, 80-92.

Good, R. H., \& Kaminski, R. A. (2002). Dynamic indicators of basic early literacy skills: Eugene, OR: Institution for the Development of Educational Achievement.

Gottardo, A., Stanovich, K. S., \& Siegel, L. S. (1996). The relationships between phonological sensitivity, syntactic processing, and verbal working memory in the reading performance of third-grade children. Journal of Experimental Child Psychology, 63, 563-582.

Gough, P. B., Hoover, W. A., \& Peterson, C. L. (1996). Some observations on a simple view of reading. In J. Oakhill \& C. Cornoldi (Eds.), Reading comprehension difficulties: Processes and interventions (Vol. 1, pp. 1-13). Mahwah, NJ: Erlbaum.

Gough, P. B., \& Tunmer, W. E. (1986). Decoding, reading and reading disability. Remedial and Special Education, 7, 6-10.

Graesser, A. C., \& Britton, B. K. (1996). Five metaphors for understanding text. In B. K. Britton \& A. C. Graesser (Eds.), Models of understanding text. (pp. 341-352). Mahwah, New Jersey: Lawrence Erlbaum.

Graham, S. (1990). The role of production factors in learning disabled student's compositions. Journal of Educational Psychology, 82, 781-791.

Graham, S., Berninger, V. W., Abbot, R. D., Abbot, S. P., \& Whitaker, D. (1997). Role of mechanics in composing of elementary school students: A new methodological approach. Journal of Educational Psychology, 89, 170-182.

Graham, S., \& Harris, K. R. (2000). The role of self-regulation and transcription skills in writing and writing development. Educational Psychologist, 35, 3-12.

Graham, S., \& Perin, D. (2007). A meta-analysis of writing instruction for adolescent students. Journal of Educational Psychology, 99, 445-476.

Graham, S., \& Weintraub, N. (1996). A review of handwriting research: Progress and prospects from 1980-1994. Educational Psychology Review, 8, 7-87.

Guthrie, J. T., \& Wigfield, A. (2005). Roles of motivation and engagement in reading comprehension assessment. In S. Paris \& K. Stahl (Eds.), Children's reading comprehension and assessment (pp. 187-213). London: Lawrence Erlbaum Associates.

Hasbrouck, J., \& Tindal, G. A. (2006). Oral reading fluency norms: A valuable assessment tool for reading teachers. The Reading Teacher, 59, 636-644.

Hayes, J. R. (2006). New directions in writing theory. In C. MacArthur, S. Graham \& J. Fitzgerald (Eds.), Handbook of writing research (Vol. 2, pp. 28-40). London: The Guildford Press.

Hidi, S., \& Hildyard, A. (1983). The comparison of oral and written production of two discourse types. Discourse Processes, 6, 91-105.

Hoover, W. A., \& Gough, P. B. (1990). The simple view of reading. Reading and Writing: An Interdisciplinary Journal, 2, 127-160.

Jenkins, J. R., Fuchs, D., van den Broeck, W., Espin, C., \& Deno, S. (2003). Sources of individual differences in reading comprehension and reading fluency. Journal of Educational Psychology, 95, 719 - 729.

Joshi, R. M., \& Aaron, P. G. (Eds.). (2006). Handbook of orthography and literacy. London: Lawrence Erlbaum Associates. 
Juel, C. (1988). Learning to read and write: A longitudinal study of 54 children from first through fourth grades. Journal of Educational Psychology, 80, 437-447.

Kamhi, A. G. (2009a). The case for the narrow view of reading. Language, Speech, and Hearing Services in Schools, 40, 174-177.

Kamhi, A. G. (2009b). Solving the reading crisis--take 2: The case for differentiated assessment. Language, Speech, and Hearing Services in Schools, 40, 212-215.

Keenan, J. M., \& Betjemann, R. S. (2006). Comprehending the gray oral reading test without reading it: Why comprehension tests should not include passage- independent items. Scientific Studies of Reading 10, 363-380.

Kellogg, R. T. (1999). Components of working memory in text production In M. Torrance \& G. C. Jeffery (Eds.), The cognitive demands of writing: Processing capacity and working memory in text production (pp. 42-61). Amsterdam, the Netherlands: Amsterdam University Press.

Kintsch, W. (1998). Comprehension: A paradigm for cognition. Cambridge, England: Cambridge University Press.

Kintsch, W., \& Kintsch, E. (2005). Comprehension. In S. Paris \& S. Stahl (Eds.), Children's reading comprehension and assessment (pp. 71-92). London: LEA.

Klauda, L. S., \& Guthrie, J. T. (2008). Relationships of three components of reading fluency to reading comprehension. Journal of Educational Psychology, 100, 310-321.

Kline, R. B. (2005). Principles and practices of structural equation modeling (2 ed.). London: The Guildford Press.

Kuhn, M. R., \& Stahl, S. A. (2003). Fluency: A review of developmental and remedial practices. Journal of Educational Psychology, 95, 3-21.

LaBerge, D., \& Samuels, S. (1974). Toward a theory of automatic information processing in reading. Cognitive Psychology, 6, 293-323.

Landerl, K., \& Wimmer, H. (2008). Development of word reading fluency and spelling in a consistent orthography: An 8-year follow-up. Journal of Educational Psychology, 100, $150-161$.

Lipson, M. Y., \& Wixson, K. K. (2003). Assessment and instruction of reading and writing difficulty. Boston: Allyn \& Bacon.

Lonigan, C. J., Burgress, S. T., \& Anthony, J. L. (2000). Development of emergent literacy and early reading skills in preschool children: Evidence from a latent-variable longitudinal study. Developmental Psychology, 36, 596-613.

Mackie, C., \& Dockrell, J. E. (2004). The nature of written language deficits in children with sli. Journal of Speech, Language, and Hearing Research, 47, 1469-1483.

Maki, H. S., Voeten, M. M., Vauras, M. M. S., \& Poskiparta, E. H. (2001). Predicting writing skill development with word recognition and preschool readiness skills. Reading and Writing: An Interdisciplinary Journal, 14, 643-672.

Mann, V., \& Wimmer, H. (2002). Phoneme awareness and pathways into literacy: A comparison of German and american children. Reading and Writing: An Interdisciplinary Journal, 15, 653-682.

McCardle, P., Scarborough, H. S., \& Catts, H. W. (2001). Predicting, explaining, and preventing children's reading difficulties. Learning Disabilities Research \& Practice, 16, 230-239.

McCutchen, D. (1996). A capacity theory of writing: Working memory in composition Educational Psychology Review, 8, 299-325. 
McCutchen, D. (2006). Cognitive factors in the development of children's writing In C. MacArthur, S. Graham \& J. Fitzgerald (Eds.), Handbook of writing research (Vol. 8, pp. 115-130). London.

McCutchen, D., Covill, A., Hoyne, S. H., \& Mildes, K. (1994). Individual differences in writing: Implications of translating fluency. Journal of Educational Psychology, 86, 256-266.

McNamara, D. (Ed.). (2007). Reading comprehension strategies: Theories, interventions, and technologies. Mahwah, NJ: Erlbaum.

Müller, K., \& Brady, S. A. (2001). Correlates of early reading performance in a transparent orthography. Reading and Writing: An Interdisciplinary Journal, 14, 757-799.

Muter, V., Hulme, C., Snowling, M., \& Stevenson, J. (2004). Phonemes, rimes, vocabulary, and grammatical skills as foundations of early reading development: Evidence from a longitudinal study. Developmental Psychology, 40, 665-681.

Nagy, W. (2007). Metalinguistic awareness and the vocabulary-comprehension connection. In R. K. Wagner, A. E. Muse \& K. R. Tannenbaum (Eds.), Acquisition of vocabulary (Vol. 4, pp. 52- 77). London: The Guilford Press.

Nation, J. K., Adams, J. W., Bowyer-Crane, C. A., \& Snowling, M. (1999). Working memory deficits in poor comprehenders reflect underlying language impairment. Journal of Experimental Child Psychology, 73, 139-158.

Nation, K., Clarke, P., Marshall, C. M., \& Durand, M. (2004). Hidden language impairments in children: Parallels between poor reading comprehension and specific language impairments? Journal of Speech, Language, and Hearing Research 47, 199-211.

NICHD (2000). Report of the national reading panel: Teaching children to read (national institute of child health and development). Retrieved 23.09.2008, from NICHD: http://www.nichd.nih.gov/publications/nrp/smallbook.cfm

NICHD (2005). Pathways to reading: The role of oral language in the transition to reading (national institute of child health and development). Developmental Psychology, 41, 428442.

Oakhill, J., \& Cain, K. (2007). Issues of causality in children's reading comprehension In D. S. McNamara (Ed.), Reading comprehension strategies: Theories, interventions, and technologies (pp. 47-72). Mahwah, NJ: Erlbaum.

Olinghouse, N., \& Leaird, J. (2009). The relationship between measures of vocabulary and narrative writing quality in second- and fourth-grade students. Reading and Writing: An Interdisciplinary Journal, 22, 545-565.

Olinghouse, N. G. (2008). Student- and instruction-level predictors of narrative writing in thirdgrade students. Reading and Writing: An Interdisciplinary Journal 21, 3-26.

Olive, T., \& Kellogg, R. T. (2002). Concurrent activation of high and low-level production processes in written composition. Memory \& Cognition, 30, 594-600.

Öney, B., \& Durgunoğlu, A. (1997). Beginning to read in Turkish: A phonologically transparent orthography. Applied Psycholinguistics, 18, 1-15.

Ouellette, G. P. (2006). What's meaning got to do with it: The role of vocabulary in word reading and reading comprehension. Journal of Educational Psychology, 98, 554-566.

Paris, S. G., Carpenter, R. D., Paris, A. H., \& Hamilton, E. (2005). Spurious and genuine correlates of children's reading comprehension. In S. G. Paris \& S. A. Stahl (Eds.), Children's reading comprehension and assessment (Vol. 6, pp. 131- 160). London: Lawrence Erlbaum Associates Publishers. 
Parodi, G. (2007). Reading-writing connections: Discourse-oriented research. Reading \& Writing: An Interdisciplinary Journal, 20, 225-250.

Pedhazur, E. J. (1982). Multiple regression in behavioral research (2nd ed.). New York: Holt, Rinehart and Winston.

Perfetti, C. A. (1997). The psycholinguistics of spelling and reading. In C. A. Perfetti, L. Rieben \& M. Fayol (Eds.), Learning to spell: Research, theory, and practice across languages (pp. 21-38). London: LEA.

Perfetti, C. A., Landi, N., \& Oakhill, J. (2005). The acquisition of reading comprehension skills. In M. Snowling \& C. Hulme (Eds.), The science of reading: A handbook (Vol. 13, pp. 227-247). Oxford: Blackwell.

Perfetti, C. A., \& Lesgold, A. M. (1977). Discourse comprehension and sources of individual differences. In M. A. Just \& P. A. Carpenter (Eds.), Cognitive processes in comprehension (pp. 141-183). Hillsdale, NJ: Erlbaum.

Perfetti, C. A., \& Roth, S. (1981). Some of the interactive processes in reading and their role in reading skill. In A. M. Lesgold \& C. A. Perfetti (Eds.), Interactive processes in reading (Vol. 11, pp. 269-297). Hillsdale, NJ: Erlbaum.

Pickering, S. J., \& Gathercole, S. E. (2001). Working memory test battery for children. UK: Psychological Corporation

Powell, D., Stainthorp, R., Stuart, M., Garwood, H., \& Quinlan, P. (2007). An experimental comparison between rival theories of rapid automatized naming performance and its relationship to reading. Journal of Experimental Child Psychology, 98, 46-68.

Proctor, P. C., Carlo, M., August, D., \& Snow, C. (2005). Native spanish-speaking children reading in english: Towards a model of comprehension. Journal of Educational Psychology, 97, 245-256.

Protopapas, A., Sideridis, G. D., Mouzaki, A., \& Simos, P. G. (2007). Development of lexical mediation in the relation between reading comprehension and word reading skills in greek. Scientific Studies of Reading, 11, 165-197.

Ransdell, S., \& Levy, M. C. (1996). Working memory constraints on writing quality and fluency. In M. C. Levy \& S. Ransdell (Eds.), The science of writing: Theories, methods, individual differences and applications (Vol. 5, pp. 93-105). New Jersey: LEA.

Raven, J. C. (1967). Standard progressive matrices. Oxford: Oxford Psychologists Press.

Raven, J. C., Court, J. H., \& Raven, J. (2006). Standard progressive matrices. Oxford, UK: Oxford Psychologists Press.

Roth, F. P. (2000). Narrative writing: Development and teaching with children with writing difficulties. Topics in Language Disorders, 20, 15-28.

Samuels, J. S. (2006). Toward a model of reading fluency. In J. S. Samuels \& A. E. Farstrup (Eds.), What research has to say about fluency instruction (pp. 24-46): The International Reading Association.

Savage, R., \& Frederickson, N. (2005). Evidence of a highly specific relationship between rapid automatic naming of digits and text-reading speed. Brain and Language, 93, 152-159.

Savage, R., Pillay, V., \& Melidona, S. (2008). Rapid serial naming is a unique predictor of spelling in children. Journal of Learning Disabilities, 41, 235-250.

Savage, R. S., \& Frederickson, N. (2006). Beyond phonology. Journal of Learning Disabilities, 39, 399-413. 
Savaşır, L., \& Şahin, N. (1995). Wechsler çocuklar için zeka ölçeği (wisc-r) [wechsler intelligence scales for children- revised]. Ankara, Turkey: Türk Psikologlar Derneği Yayını.

Seigneuric, A., \& Ehrlich, M. (2005). Contribution of working memory capacity to children's reading comprehension. Reading and Writing: An Interdisciplinary Journal, 18, 617-656.

Seigneuric, A., Ehrlich, M., Oakhill, J. V., \& Yuill, N. M. (2000). Working memory resources and children's reading comprehension. Reading and Writing: An Interdisciplinary Journal, 13, 81-103.

Seymour, P. H. K., Aro, M., \& Erskine, J. M. (2003). Foundation literacy acquisition in european orthographies. British Journal of Psychology, 94, 143-174.

Shanahan, T. (1984). Nature of reading-writing relations: An exploratory multivariate analysis. Journal of Educational Psychology, 76.

Shanahan, T., \& Lomax, D. (1986). An analysis and comparison of theoretical models of reading-writing relationship Journal of Educational, 78 116-123.

Shankweiler, D. P., \& Fowler, A. E. (2004). Questions people ask about the role of phonological processes in learning to read. Reading and Writing: An Interdisciplinary Journal, 17, 483-515.

Share, D. L. (1995). Phonological recoding and self-teaching: Sine qua non of reading acquisition. Cognition, 55, 151-218.

Spear-Swerling, L. (2006). Children's reading comprehension and oral reading fluency in easy text. Reading and Writing: An Interdisciplinary Journal, 19, 199-220.

SPO (1996). Census of population: Social and economic characteristics of population. Turkish Republic of Northern Cyprus: TRNC Prime Ministry, State Planning Organization, Statistics and Research Department.

Stainthorp, R., \& Rauf, N. (2009). An investigation of the influence of the transcription skills of handwriting and spelling on the quality of text writing by girls and boys in key stage 2 . Handwriting Today, 8, 8-13.

Stanovich, K. E., Cunningham, A. E., \& Freeman, D. J. (1984). Intelligence, cognitive skills, and early reading progress. Reading Research Quarterly, 19, 278-303.

Stothard, S. E., \& Hulme, C. (1992). Reading comprehension difficulties in children. Reading and Writing: An Interdisciplinary Journal, 4, 245-256.

Sulzby, E. (1985). Kindergartners as writers and readers. In M. Farr (Ed.), Advances in writing research: Vol 1. Children's early writing development (pp. 127-199). Norwood, NJ: Ablex.

Swanson, H. L., \& Berninger, V. W. (1996). Individual differences in children's working memory and writing skills. Journal of Experimental Child Psychology, 63, 358-385.

Torgesen, J. K., Wagner, R. K., \& Rashotte, C. A. (1994). Longitudinal studies of phonological processing and reading. Journal of Learning Disabilities, 27, 276-286.

Torgesen, J. K., Wagner, R. K., Rashotte, C. A., Burgess, S. R., \& Hecht, S. A. (1997). Contributions of phonological awareness and rapid automatic naming ability to the growth of word-reading skills in second-to fifth-grade children. Scientific Studies of Reading, 1, 161-185.

Torgeson, J. K., Wagner, R., \& Rashotte, C. A. (1999). Towre: Test of word reading efficiency. Austin, Texas: PRO-ED.

Treiman, R. (1993). Beginning to spell: A study of first-grade children. New York: Oxford University Press. 
Treiman, R., \& Barry, C. (2000). Dialect and orthography: Some differences between american and british spellers. Journal of Experimental Psychology: Learning, Memory and Cognition, 26, 1423-1430.

Treiman, R., \& Kessler, B. (2005). Writing systems and spelling development. In M. Snowling \& C. Hulme (Eds.), The science of reading (pp. 120-134). Oxford: Blackwell.

van Bon, W. H. J., \& van Leeuwe, J. F. J. (2003). Assessing phonemic awareness in kindergarten: The case for the phoneme recognition task. Applied Psycholinguistics, 24, 195-219.

Verhagen, W., Aarnoutse, C., \& Van Leeuwe, J. (2008). Phonological awareness and naming speed in the prediction of Dutch children's word recognition. Scientific Studies of Reading, 12, 301-324.

Wagner, R. K., Muse, A. E., \& Tannenbaum, K. R. (2007). Promising avenues for better understanding implications of vocabulary development for reading comprehension. In R. K. Wagner, A. E. Muse \& K. R. Tannenbaum (Eds.), Vocabulary acquisition (pp. 276291). London: The Guildford Press.

Wagner, R. K., Torgesen, J. K., Rashotte, C. A., Hecht, S. A., Barker, T. A., Burgess, S. R., Donahue, J., \& Garon, T. (1997). Changing relations between phonological processing abilities and word-level reading as children develop from beginning to skilled readers: A 5-year longitudinal study. Developmental Psychology, 33, 468-479.

Walczyk, J. (1994). The development of verbal efficiency, metacognitive strategies, and their interplay. Educational Psychology Review, 6, 173-189.

Walczyk, J. (2000). The interplay between automatic and control processes in reading. Reading Research Quarterly, 35, 554-566.

Wechsler, D. (1996). Wechsler objective language dimensions. London: The Psychological Corporation.

Wechsler, D. (2005). Wechsler individual achievement test (second UK edition) London, UK: Harcourt Publishers.

Wimmer, H. (1993). Characteristics of developmental dyslexia in a regular writing system. Applied Psycholinguistics, 14, 1-33.

Wimmer, H. (1996). The early manifestation of developmental dyslexia: Evidence from German children. Reading and Writing: An Interdisciplinary Journal, 8, 171-188.

Wimmer, H., \& Mayringer, H. (2002). Dysfluent reading in the absence of spelling difficulties: A specific disability in regular orthography. Journal of Educational Psychology, 94, 272277.

Wolf, M., Bowers, P. G., \& Biddle, K. (2000). Naming-speed processes, timing, and reading: A conceptual review. Journal of Learning Disabilities, 33, 387-407.

Wolf, M., \& Katzir-Cohen, T. (2001). Reading fluency and its intervention. Scientific Studies of Reading, 5, 211-239. 


\section{Footnotes}

${ }^{1}$ A series of separate SEM analysis for each wave further confirmed that the observed pattern of relationships between the predictor and outcome variables were comparable across the two cohorts.

${ }^{2}$ The bivariate correlation coefficients of age with both reading fluency and reading comprehension were positive, yet in Figures 1 and 3 the path coefficients from age to reading outcomes emerged as negative. These findings suggest that age was acting as a suppressor variable in these models, which is not an uncommon finding in multivariate research with highly correlated predictor variables (for further information, see Cohen \& Cohen, 1983; Kline, 2005; Pedhazur, 1982). The negative suppressor effect of age in this context arguably serves to remove the irrelevant effect of age and thereby reduce the scores of those who scored higher on the reading outcome measures simply due to their older age (see Pedhazur, 1982).

${ }^{3}$ It is notable that the repetition of the SEM analysis with working memory scores based on the total number of recalled words rather than by accurate number of trials yielded the same results. 


\section{Appendix}

Examples from the Experimental Tasks

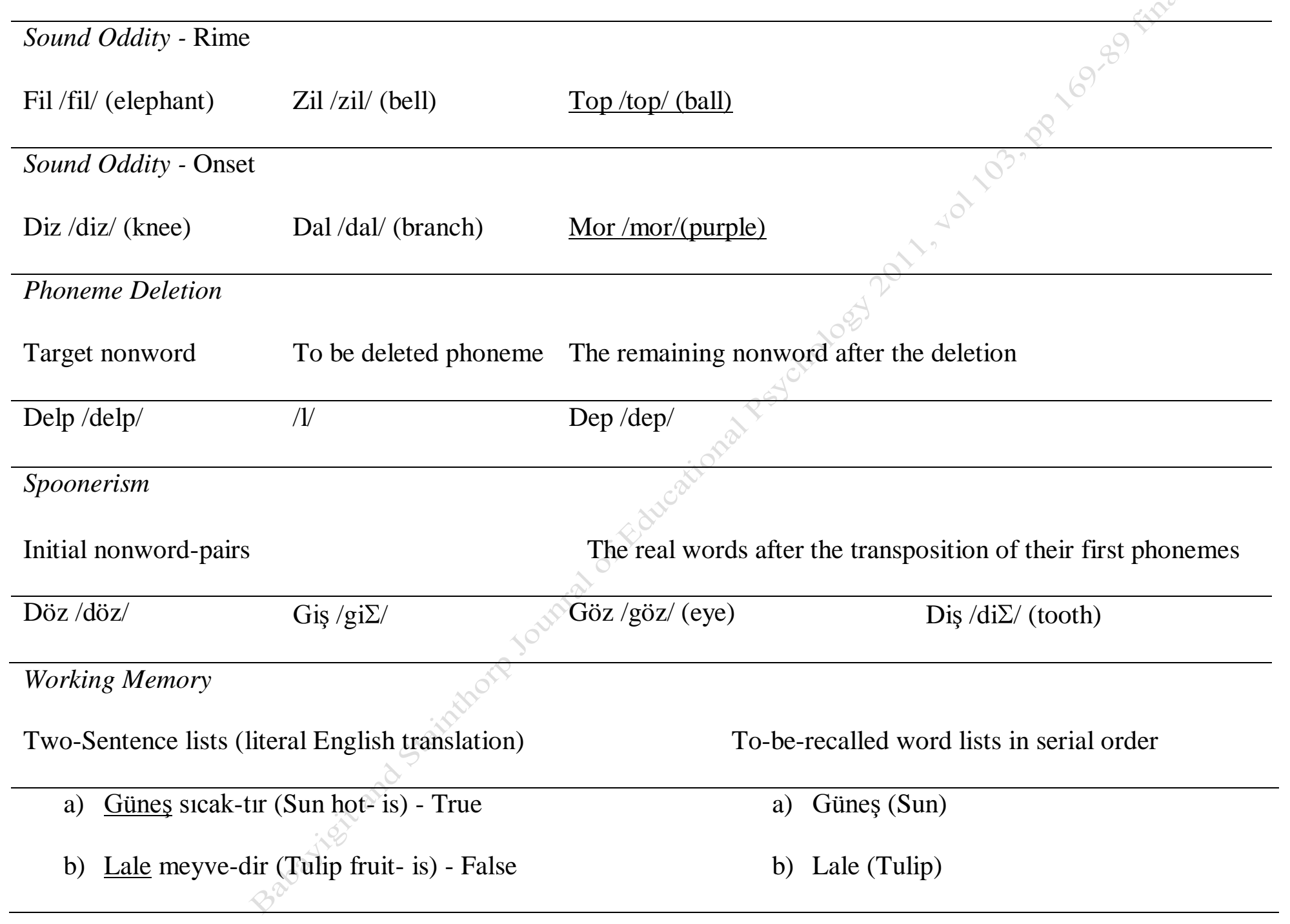


Table 1

Descriptive Statistics and Time of Testing

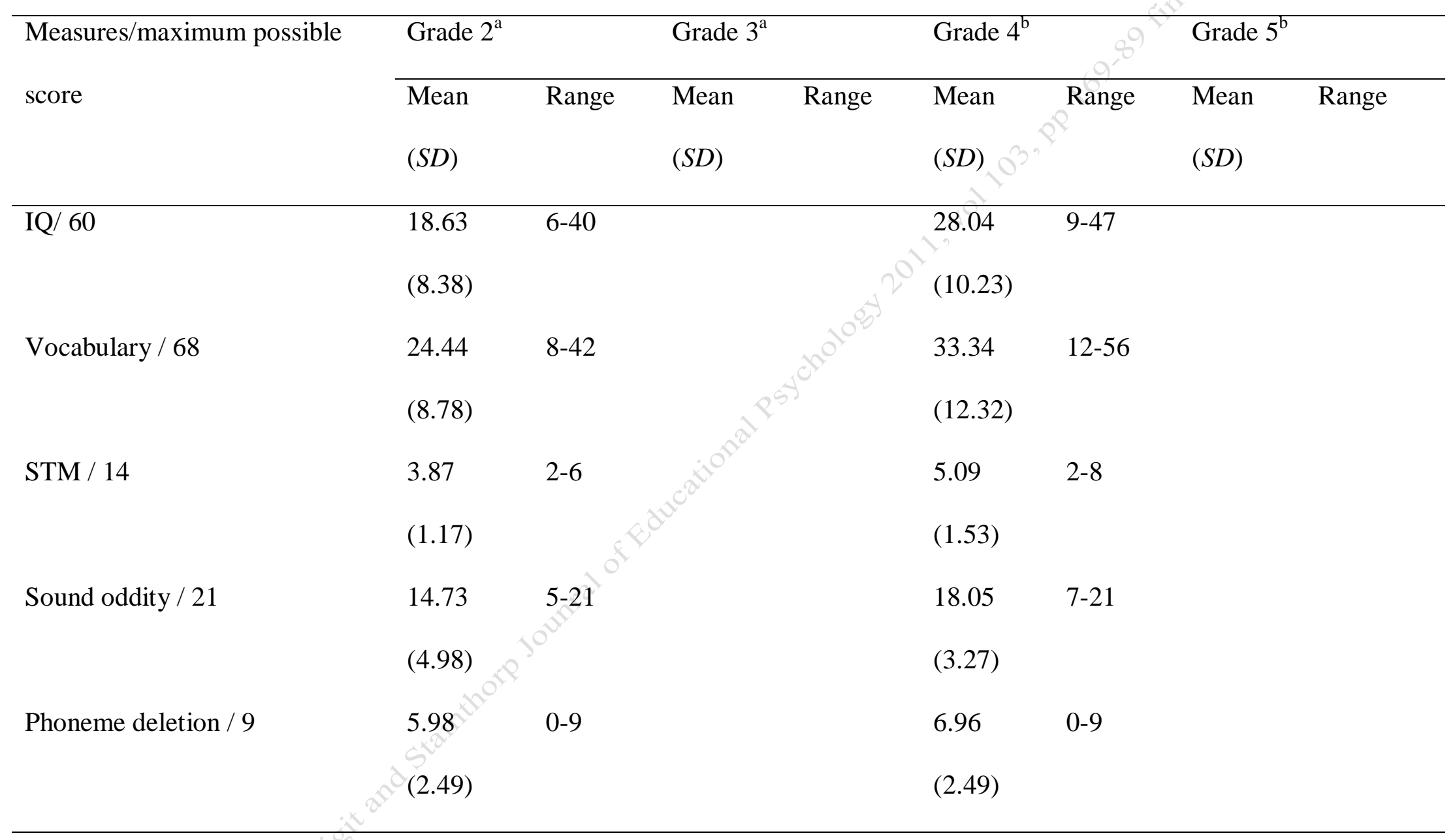




\begin{tabular}{|c|c|c|c|c|c|c|c|c|}
\hline Measures/maximum possible & Grade $2^{\mathrm{a}}$ & & Grade $3^{\mathrm{a}}$ & & Grade $4^{b}$ & & Grade $5^{b}$ & \\
\hline score & $\begin{array}{l}\text { Mean } \\
(S D)\end{array}$ & Range & $\begin{array}{l}\text { Mean } \\
(S D)\end{array}$ & Range & $\begin{array}{l}\text { Mean } \\
(S D)\end{array}$ & Range & $\begin{array}{l}\text { Mean } \\
(S D)\end{array}$ & Range \\
\hline Spoonerism / 12 & $\begin{array}{l}4.51 \\
(3.51)\end{array}$ & $0-12$ & & & $\begin{array}{l}6.07 \\
(4.40)\end{array}$ & $0-12$ & & \\
\hline RAN-Digits / na & $\begin{array}{l}38.16 \\
(8.34)\end{array}$ & $24-61$ & & & $\begin{array}{l}27.44 \\
(5.12)\end{array}$ & $19-39$ & & \\
\hline RAN-Letters /na & $\begin{array}{l}36.99 \\
(7.56)\end{array}$ & $20-54$ & & & $\begin{array}{l}27.04 \\
(4.80)\end{array}$ & $19-38$ & & \\
\hline Working memory / 12 & $\begin{array}{l}3.41 \\
(1.85)\end{array}$ & $0-8$ & & & $\begin{array}{l}4.73 \\
(1.28)\end{array}$ & $2-78$ & & \\
\hline Listening comprehension / 14 & $\begin{array}{l}7.22 \\
(2.21)\end{array}$ & $3-11$ & & & $\begin{array}{l}8.20 \\
(2.28)\end{array}$ & 4-12 & & \\
\hline Word reading ${ }^{\mathrm{c}} / \mathrm{na}$ & $\begin{array}{l}26.85 \\
(9.73)\end{array}$ & $8-54$ & $\begin{array}{l}32.22 \\
(10.14)\end{array}$ & $17-63$ & $\begin{array}{l}40.43 \\
(9.96)\end{array}$ & $15-60$ & $\begin{array}{l}44.18 \\
(10.80)\end{array}$ & $20-74$ \\
\hline
\end{tabular}




\begin{tabular}{|c|c|c|c|c|c|c|c|c|}
\hline Measures/maximum possible & Grade $2^{\mathrm{a}}$ & & Grade $3^{\circ}$ & & Grade $4^{b}$ & & Grade 5 & \\
\hline score & $\begin{array}{l}\text { Mean } \\
(S D)\end{array}$ & Range & $\begin{array}{l}\text { Mean } \\
(S D)\end{array}$ & Range & $\begin{array}{l}\text { Mean } \\
(S D)\end{array}$ & Range & $\begin{array}{l}\text { Mean } \\
(S D)\end{array}$ & Range \\
\hline Nonword reading $^{\mathrm{c}} / \mathrm{na}$ & $\begin{array}{l}21.67 \\
(7.10)\end{array}$ & $11-43$ & $\begin{array}{l}25.82 \\
(7.56)\end{array}$ & $15-53$ & $\begin{array}{l}29.98 \\
(8.46)\end{array}$ & $7-47$ & $\begin{array}{l}31.10 \\
(9.12)\end{array}$ & $12-55$ \\
\hline Agglutinated word reading ${ }^{c} /$ na & $\begin{array}{l}18.96 \\
(6.73)\end{array}$ & $9-40$ & $\begin{array}{l}22.78 \\
(7.82)\end{array}$ & $\begin{array}{r}13-53 \\
8\end{array}$ & $\begin{array}{l}29.71 \\
(8.12)\end{array}$ & $13-47$ & $\begin{array}{l}32.31 \\
(9.59)\end{array}$ & $13-53$ \\
\hline Text reading fluency ${ }^{c} /$ na & $\begin{array}{l}56.09 \\
(8.62)\end{array}$ & $42-86$ & $\begin{array}{l}61.79 \\
(9.40)\end{array}$ & $45-92$ & $\begin{array}{l}67.04 \\
(10.34)\end{array}$ & $36-87$ & $\begin{array}{l}71.11 \\
(10.17)\end{array}$ & $46-92$ \\
\hline Text reading accuracy /174 & $\begin{array}{l}167.57 \\
(5.17)\end{array}$ & 149-174 & $\begin{array}{l}168.64 \\
(3.78)\end{array}$ & $158-174$ & $\begin{array}{l}168.47 \\
(5.48)\end{array}$ & $146-174$ & $\begin{array}{l}168.75 \\
(4.05)\end{array}$ & $156-174$ \\
\hline Reading comprehension / 26 & $\begin{array}{l}13.00 \\
(4.42)\end{array}$ & $4-24$ & $\begin{array}{l}15.76 \\
(4.61)\end{array}$ & $5-25$ & $\begin{array}{l}15.67 \\
(4.48)\end{array}$ & $4-23$ & $\begin{array}{l}16.08 \\
(3.97)\end{array}$ & $8-22$ \\
\hline Spelling accuracy / 13 & $\begin{array}{l}7.69 \\
(2.15)\end{array}$ & $2-12$ & $\begin{array}{l}7.91 \\
(2.56)\end{array}$ & $3-12$ & $\begin{array}{l}9.56 \\
(1.71)\end{array}$ & $3-13$ & $\begin{array}{l}9.84 \\
(2.10)\end{array}$ & $3-13$ \\
\hline
\end{tabular}




\begin{tabular}{|c|c|c|c|c|c|c|c|c|}
\hline \multirow{2}{*}{$\begin{array}{l}\text { Measures/maximum possible } \\
\text { score }\end{array}$} & \multicolumn{2}{|c|}{ Grade $2^{\mathrm{a}}$} & \multicolumn{2}{|c|}{ Grade $3^{\mathrm{a}}$} & \multicolumn{2}{|l|}{ Grade $4^{b}$} & \multicolumn{2}{|c|}{ Grade $5^{b}$} \\
\hline & $\begin{array}{l}\text { Mean } \\
(S D)\end{array}$ & Range & $\begin{array}{l}\text { Mean } \\
(S D)\end{array}$ & Range & $\begin{array}{l}\text { Mean } \\
(S D)\end{array}$ & Range & $\begin{array}{l}\text { Mean } \\
(S D)\end{array}$ & Range \\
\hline Writing-error rate ${ }^{\mathrm{d}} / 100 \%$ & $\begin{array}{l}0.10 \\
(0.07)\end{array}$ & $0.0-0.4$ & & & $\begin{array}{l}0.09 \\
(0.11)\end{array}$ & $0.0-0.5$ & & \\
\hline Writing-fluency ${ }^{\mathrm{e}} / \mathrm{na}$ & $\begin{array}{l}7.12 \\
(1.98)\end{array}$ & $2-12$ & & & $\begin{array}{l}10.21 \\
(2.66)\end{array}$ & $5-16$ & & \\
\hline Writing-content / 9 & $\begin{array}{l}4.07 \\
(1.82)\end{array}$ & $2-8$ & $\begin{array}{l}4.29 \\
(1.56)\end{array}$ & $2-8$ & $\begin{array}{l}4.84 \\
(1.49)\end{array}$ & $2-8$ & $\begin{array}{l}4.96 \\
(1.43)\end{array}$ & $2-8$ \\
\hline
\end{tabular}

Note. IQ = Raven's Standard Progressive Matrices (raw scores); na $=$ Not applicable $;{ }^{\mathrm{a}}=$ Cohort $\mathrm{a} ;{ }^{\mathrm{b}}=$ Cohort $\mathrm{b} ;{ }^{\mathrm{c}}=\mathrm{accurately}$ read words per minute; ${ }^{\mathrm{d}}=$ the number of spelling errors divided by the total number of written words; ${ }^{\mathrm{e}}=$ the number of words written per minute. 
Table 2

Partial Correlations Coefficients between the Measures at Time 1 after Controlling for Age

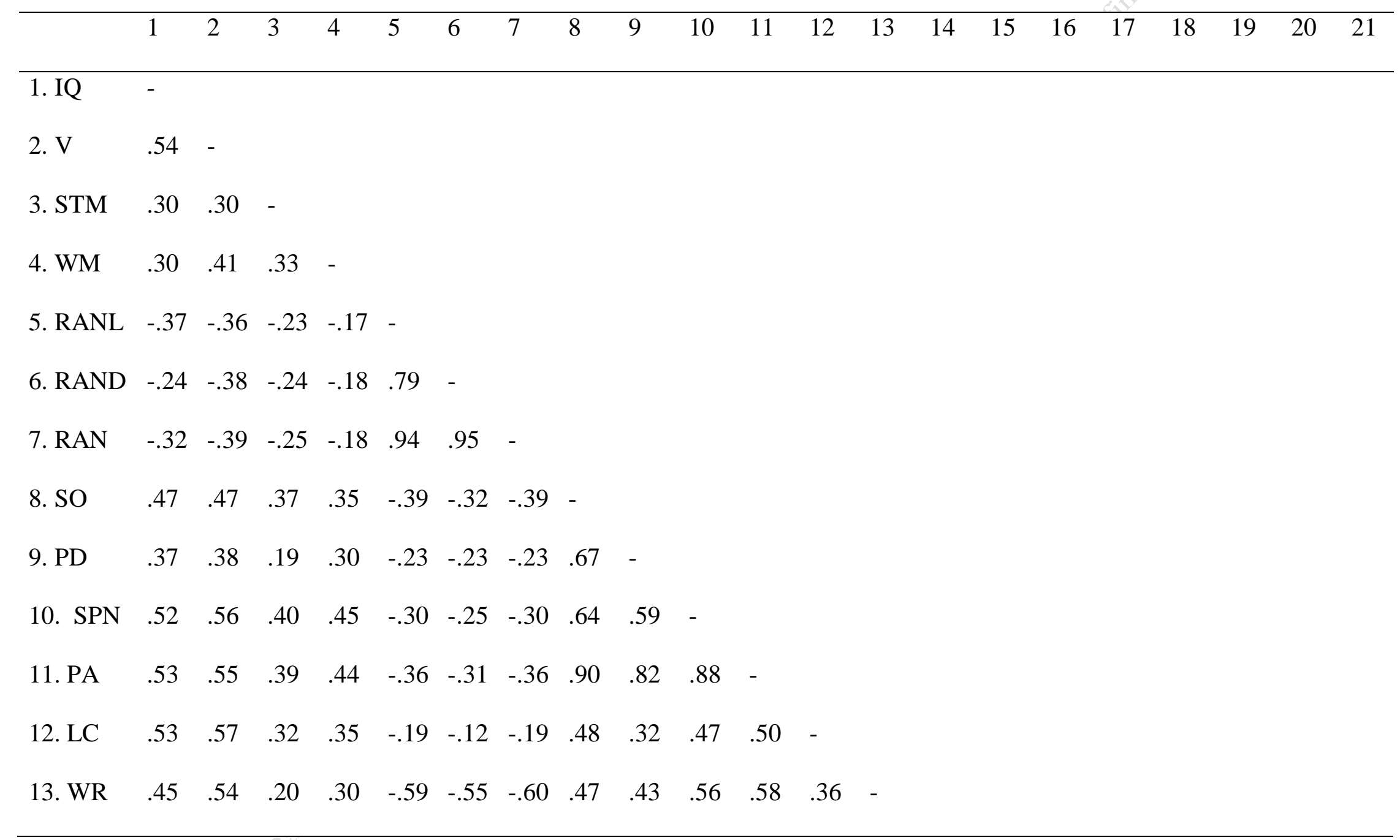




\begin{tabular}{|c|c|c|c|c|c|c|c|c|c|c|c|c|c|c|c|c|c|c|c|c|c|}
\hline & 1 & 2 & 3 & 4 & 5 & 6 & 7 & 8 & 9 & 10 & 11 & 12 & 13 & 14 & 15 & 16 & 17 & 18 & 19 & 20 & 21 \\
\hline 14. NWR & .38 & .44 & .23 & .24 & -.62 & -.58 & -.63 & .47 & .40 & .56 & .57 & .27 & .82 & - & & & & & & & \\
\hline 15. AWR & .45 & .51 & .21 & .29 & -.60 & -.56 & -.62 & .43 & .35 & .56 & .53 & .29 & .87 & .84 & - & & & & & & \\
\hline 16. TRF & .52 & .54 & .20 & .28 & -.58 & -.51 & -.58 & .47 & .42 & .57 & .58 & .36 & .86 & .79 & .86 & - & & & & & \\
\hline 17. $\mathrm{RF}$ & .45 & .53 & .19 & .30 & -.65 & -.61 & -.67 & .47 & .37 & .58 & .57 & .32 & .95 & .92 & .95 & .94 & - & & & & \\
\hline 18. SA & .23 & .38 & .24 & .33 & -.34 & -.33 & -.35 & .33 & .40 & .46 & .47 & .23 & .33 & .37 & .34 & .35 & .36 & - & & & \\
\hline 19. $\mathrm{RC}$ & .41 & .55 & .24 & .40 & -.14 & -.07 & -.11 & .44 & .42 & .44 & .50 & .56 & .31 & .25 & .28 & .37 & .25 & .17 & - & & \\
\hline 20. WER & -.26 & -.28 & -.19 & -.22 & .19 & .21 & .21 & -.30 & -.28 & -.40 & -.38 & -.04 & -.47 & -.48 & -.52 & -.51 & -.45 & -.32 & -.04 & - & \\
\hline 21. WF & .23 & .30 & .23 & .15 & -.36 & -.40 & -.41 & .21 & .03 & .27 & .23 & .07 & .39 & .37 & .41 & .39 & .35 & .33 & -.02 & -.20 & - \\
\hline 22. WC & .38 & .39 & .23 & .35 & -.27 & -.17 & -.23 & .35 & .27 & .36 & .39 & .41 & .24 & .24 & .27 & .30 & .28 & .35 & .45 & -.14 & .22 \\
\hline
\end{tabular}

Note. IQ = Raven's Standard Progressive Matrices; V = Vocabulary; STM = Short-term memory; WM = Working memory; RANL = Rapid Automatized Naming-letters; RAND = Rapid Automatized Naming-digits; RAN = Rapid Automatized Naming-composite; SO = Sound oddity; $\mathrm{PD}=$ Phoneme deletion; $\mathrm{SPN}=$ Spoonerism; $\mathrm{PA}=$ Phonological awareness-composite LC $=$ Listening comprehension; $\mathrm{WR}=\mathrm{Word}$ reading; NWR = Nonword reading; AWR = Agglutinated word reading; TRF $=$ Text reading fluency; RF $=$ Reading fluency-composite SA $=$ Spelling accuracy; RC = Reading comprehension; WER = Writing-error rate; WF = Writing-fluency; WC = Writing-content. Correlation coefficients larger than .21 are statistically significant at .05 . 
Table 3

Partial Correlations Coefficients between the Literacy Outcome Measures at Time 2 after

Controlling for Age

\begin{tabular}{lllllllll}
\hline Measures at Time 2 & 1 & 2 & 3 & 4 & 5 & 6 & 7 & 8
\end{tabular}

1. Word reading

2. Nonword reading $.80-$

3. Agglutinated word reading $.85 \quad .85 \quad-$

4. Text reading fluency $\begin{array}{llll}.86 & .79 \quad .89 & -\end{array}$

5. Reading fluency-composite $\begin{array}{lllll}.94 & .91 & .95 & .94 & -\end{array}$

6. Spelling accuracy $\begin{array}{lllll}.42 & .38 & .36 & .41 & .40\end{array}$

7. Reading comprehension $\begin{array}{lllllll}.37 & .29 & .32 & .36 & .36 & .32 & -\end{array}$

8. Writing-content $.25 \quad .28 \quad .4$ $.35 \quad .39$ $.20 \quad .38$

Note. Correlation coefficients larger than .21 are statistically significant at .05 and those above .28 and .35 are significant at .01 and .001 , respectively. 
Running head: COGNITIVE-LINGUISTIC SKILLS AND LITERACY SKILLS

62

Table 4

Partial Correlations Coefficients between the Time 1 and Time 2 Measures after Controlling for Age

\begin{tabular}{|c|c|c|c|c|c|c|c|c|}
\hline \multirow[b]{2}{*}{ Time 1 Measures } & \multicolumn{8}{|c|}{ Time 2 Measures } \\
\hline & $\overline{W R}$ & NWR & AWR & TRF & $\mathrm{RF}$ & $\mathrm{SA}$ & $\mathrm{RC}$ & $\mathrm{WC}$ \\
\hline 1. IQ & .43 & .42 & .43 & .45 & .46 & .30 & .47 & .40 \\
\hline 2. $\mathrm{V}$ & .59 & .45 & .50 & .54 & .56 & .28 & .46 & .35 \\
\hline 3. STM & .25 & .30 & .22 & .17 & .19 & .14 & .16 & .04 \\
\hline 4. WM & .35 & .32 & .39 & .29 & .30 & .36 & .33 & .32 \\
\hline 5. RANL & -.52 & -.60 & -.59 & -.61 & -.61 & -.34 & -.14 & -.30 \\
\hline 6. RAND & -.51 & -.61 & -.58 & -.59 & -.61 & -.29 & -.03 & -.19 \\
\hline 7. RAN & -.54 & -.64 & -.62 & -.64 & -.65 & -.33 & -.09 & -.26 \\
\hline 8. $\mathrm{SO}$ & .45 & .43 & .39 & .44 & .46 & .49 & .50 & .36 \\
\hline 9. $\mathrm{PD}$ & .39 & .30 & .27 & .32 & .35 & .41 & .44 & .26 \\
\hline 10. SPN & .56 & .49 & .50 & .54 & .56 & .40 & .38 & .29 \\
\hline 11. PA & .56 & .50 & .48 & .52 & .55 & .52 & .51 & .36 \\
\hline 12. LC & .39 & .26 & .29 & .38 & .36 & .21 & .59 & .33 \\
\hline
\end{tabular}


Running head: COGNITIVE-LINGUISTIC SKILLS AND LITERACY SKILLS

63

\begin{tabular}{|c|c|c|c|c|c|c|c|c|}
\hline \multirow[b]{2}{*}{ Time 1 Measures } & \multicolumn{8}{|c|}{ Time 2 Measures } \\
\hline & WR & NWR & AWR & TRF & $\mathrm{RF}$ & $\mathrm{SA}$ & $\mathrm{RC}$ & $\mathrm{WC}$ \\
\hline 13. WR & .86 & .82 & .82 & .85 & .89 & .37 & .35 & .35 \\
\hline 14. NWR & .73 & .84 & .80 & .77 & .83 & .34 & .24 & .28 \\
\hline 15. AWR & .80 & .79 & .84 & .80 & .86 & .35 & .28 & .42 \\
\hline 16. TRF & .83 & .81 & .86 & .90 & .90 & .32 & .40 & .39 \\
\hline 17. RF & .86 & .86 & .88 & .89 & .93 & .37 & .34 & .38 \\
\hline 18. SA & .35 & .32 & .33 & .33 & .35 & .50 & .16 & .20 \\
\hline 19. $\mathrm{RC}$ & .22 & .19 & .23 & .24 & .23 & .14 & .66 & .33 \\
\hline 20. WER & -.32 & -.40 & -.44 & -.40 & -.41 & -.32 & -.14 & -.20 \\
\hline 21. WF & .35 & .36 & .49 & .41 & .43 & .21 & -.03 & .17 \\
\hline 22. WC & .31 & .21 & .30 & .32 & .32 & .30 & .35 & .54 \\
\hline
\end{tabular}

Note. IQ = Raven's Standard Progressive Matrices; V = Vocabulary; STM = Shor-term memory; WM = Working memory; RANL = Rapid Automatized Naming-letters; RAND = Rapid Automatized Naming-digits; RAN = Rapid Automatized Naming-composite; SO = Sound oddity; $\mathrm{PD}=$ Phoneme deletion; $\mathrm{SPN}=$ Spoonerism; $\mathrm{PA}=$ Phonological awareness-composite LC $=$ Listening comprehension; $\mathrm{WR}=\mathrm{Word}$ reading; NWR = Nonword reading; AWR = Agglutinated word reading; TRF = Text reading fluency; RF = Reading fluency-composite; SA = Spelling accuracy; RC = Reading comprehension; WER = Writing-error rate; WF = Writing-fluency; WC = Writing-content. 
Running head: COGNITIVE-LINGUISTIC SKILLS AND LITERACY SKILLS

64

Note. Correlation coefficients larger than .21 are statistically significant at .05 and those above .28 and .35 are significant at .01 and .001 , respectively. 
Figure 1. The hypothesized path model of predictors of Time 2 reading fluency skills from Time 1 predictor measures. $\mathrm{CFI}=$ Comparative fit index; RMSEA = Root mean square error of approximation. IQ = Raven's Standard Progressive Matrices; PA = Phonological awareness-composite measure; RAN = Rapid Automatized Naming-composite measure. $\mathrm{T} 1=$ Time 1. T2 = Time 2 .

$* p<.01 . * * p<.001$.

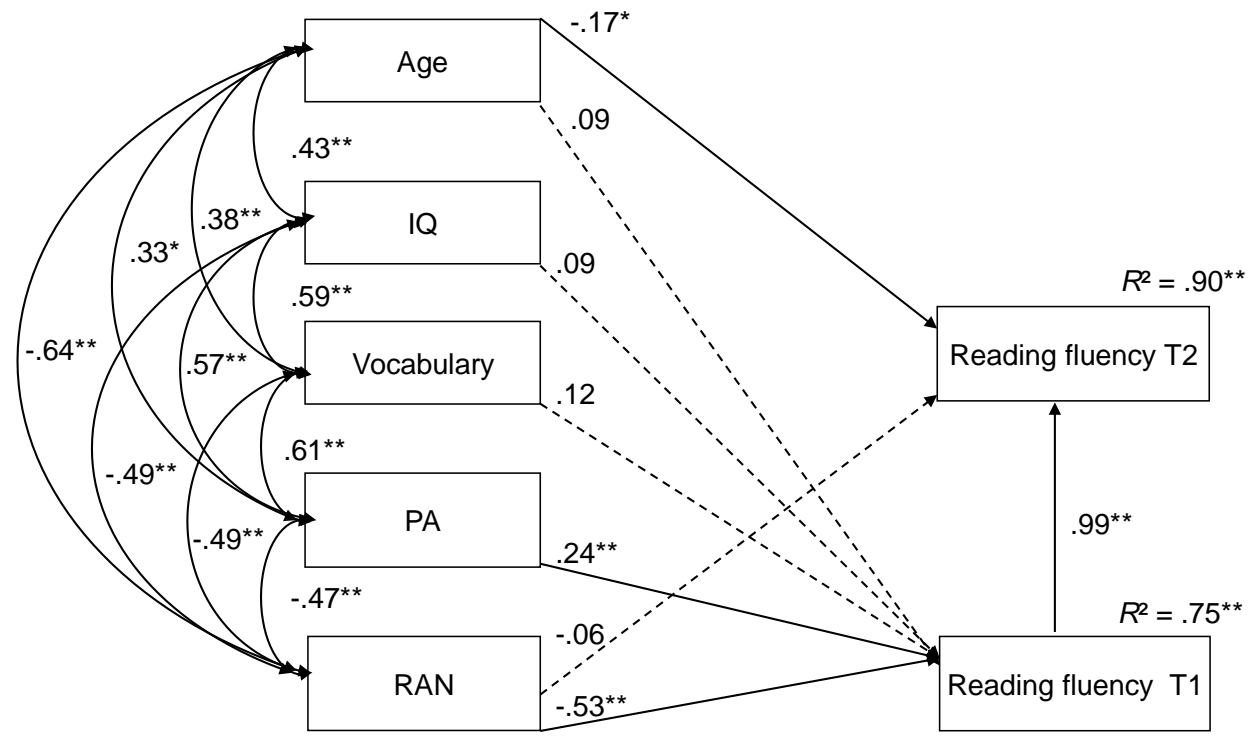

$\chi^{2}(3, N=103)=4.19, \mathrm{~ns} ; \mathrm{CFI}=.998 ; \mathrm{RMSEA}=.058$ 
Figure 2. The hypothesized path model of predictors of Time 2 spelling skills from Time 1 predictor measures. $\mathrm{CFI}=$ Comparative fit index; RMSEA $=$ Root mean square error of approximation. IQ = Raven's Standard Progressive Matrices; PA = Phonological awarenesscomposite measure; RAN = Rapid Automatized Naming-composite measure; $\mathrm{T} 1$ = Time 1; $\mathrm{T} 2=$ Time 2.

$* p<.05 . * * p<.01 . * * * p<.001$.

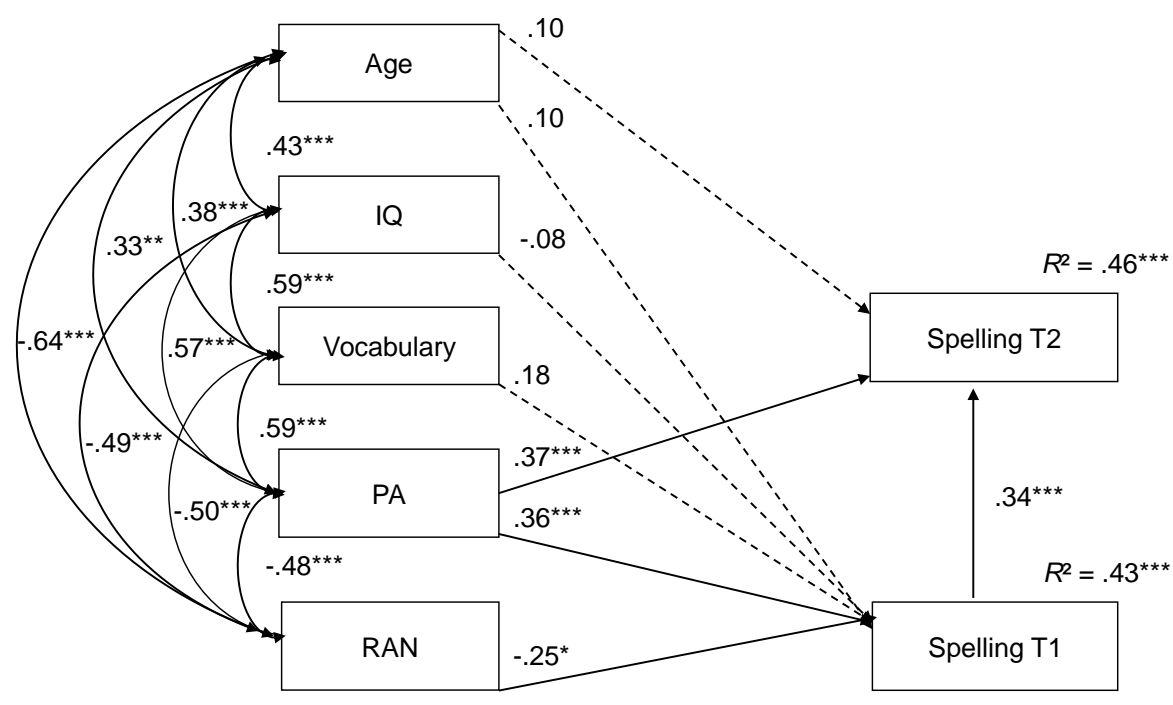

$\chi^{2}(3, N=103)=2.94, \mathrm{~ns} ; \mathrm{CFI}=1.00 ; \mathrm{RMSEA}=.00$ 
Figure 3. The hypothesized path model of predictors of Time 2 reading comprehension skills from Time 1 predictor measures. $\mathrm{CFI}=$ Comparative fit index; RMSEA = Root mean square error of approximation. IQ = Raven's Standard Progressive Matrices; T1 = Time 1; T2 = Time 2.

${ }^{\mathrm{a}} p=.071{ }^{*} p<.05 . * * p<.01 . * * * p<.001$.

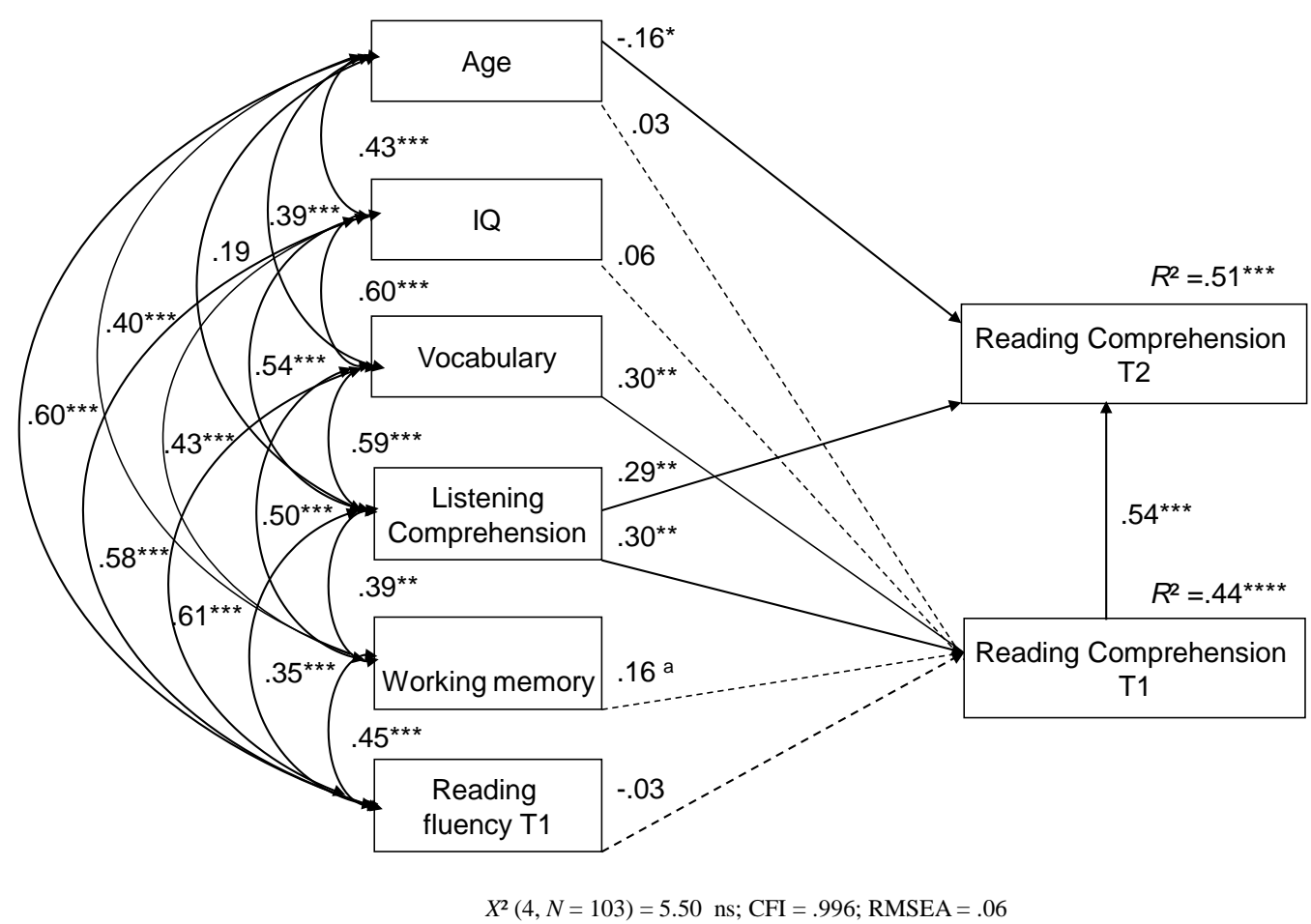


Figure 4. The hypothesized path model of predictors of Time 2 text writing skills from Time 1 predictor measures. $\mathrm{CFI}=$ Comparative fit index; $\mathrm{RMSEA}=$ Root mean square error of approximation. IQ = Raven's Standard Progressive Matrices; T1 = Time 1; T2 = Time 2. $* p<.001$.

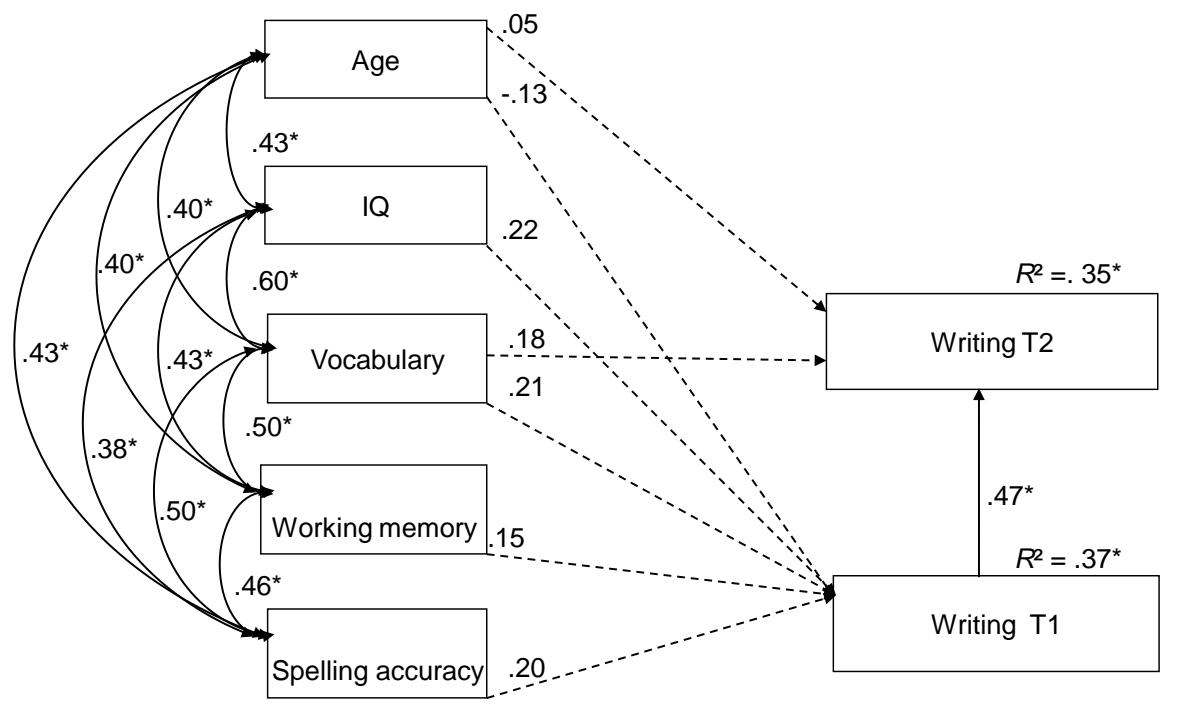

$X^{2}(3, N=103)=2.02 \mathrm{~ns} ;$ CFI $=.100 ;$ RMSEA $=.00$ 